\title{
Three new sympatric species of Remipedia (Crustacea) from Great Exuma Island, Bahamas Islands
}

\author{
Stefan Koenemann ${ }^{1}$, Thomas M. Iliffe ${ }^{2}$ \& Joris van der $\mathrm{Ham}^{3}$ \\ ${ }^{1}$ Institute of Biodiversity and Ecosystem Dynamics, University of Amsterdam, P.O. Box 94766, 1090 GT \\ Amsterdam, The Netherlands, corresponding author (koenemann@science.uva.nl); ${ }^{2}$ Department of Marine \\ Biology, Texas A\&M University at Galveston, Galveston, TX 77553-1675, USA; ${ }^{3}$ Department of Biology, \\ University of Louisiana at Lafayette, 300 East St. Mary Blvd., Lafayette, LA 70504, USA
}

Keywords: Crustacea, Remipedia, Speleonectidae, Speleonectes, new species, Bahamas, anchihaline caves, sympatry, biogeography, evolutionary history

\begin{abstract}
Three new sympatric species of remipede crustaceans, Speleonectes tanumekes, Speleonectes parabenjamini and Speleonectes minnsi, are described from an anchihaline cave on Great Exuma Island in the central Bahamas. Speleonectes tanumekes is a comparatively long and slender species distinguished by the largest number of trunk segments found in remipedes to date. Speleonectes parabenjamini is morphologically closely related to Speleonectes benjamini, but differs from the latter species by several distinct autapomorphies. Speleonectes minnsi is characterized by comparatively robust maxillules. The occurrence of three sympatric species is a remarkable record for the Remipedia adding to a total of 10 sympatric taxa. We discuss the high diversity of remipedes in the larger West Indian region with regard to their evolutionary history and origin.
\end{abstract}

\section{Contents}

Introduction

Abbreviations and definition of terms $\quad 227$

Systematics $\quad 228$

Remipedia $\quad 228$

Nectiopoda 228

Speleonectidae 228

Speleonectes 229

Speleonectes tanumekes n. sp. 229

Speleonectes parabenjamini $\mathrm{n}$. sp. $\quad 235$

Speleonectes minnsi fi. sp. 241

Ecological profile of the type locality $\quad 247$

Some remarks on the biogeography and evolutionary

history of Remipedia

Acknowledgements

References

\section{Introduction}

To date, the crustacean class Remipedia Yager, 1981, is composed of two families, the Speleonectidae Yager, 1981, including nine species in three genera, and the Godzilliidae Schram, Yager \& Emerson, 1986, with three species in three genera. The first remipede was discovered in an anchihaline cave on the Bahamas Islands (Yager, 1981). Between 1980 and 1999, 11 additional species were described. All currently known Remipedia inhabit subtropical anchihaline caves. Their distribution is disjunct, comprising recorded localities in the larger Caribbean region, western Australian, and on the Canary Islands.

We describe three new sympatric species of remipedes, Speleonectes tanumekes, Speleonectes parabenjamini and Speleonectes minnsi, including detailed drawings and SEM images. The new species were found during a recent diving expedition on Great Exuma Island located in the central Bahamas. All specimens were collected from the same anchihaline cave between 33 and $43 \mathrm{~m}$ depth. The implications of this new record are discussed with regard to the biogeography and evolutionary history of the Remipedia.

\section{Abbreviations and definitions of terms \\ JvdH Joris van der Ham \\ ZMA Zoological Museum Amsterdam \\ Elbow Term referring to the main point of flexure in maxillules, maxillae and maxillipeds.}


Tagmosis of maxillae and maxillipeds is a condition characterized by distinct size and shape differences between the segment proximal to the elbow and those distal to the elbow. In tagmatized appendages, the proximal segment is much longer and wider than the distal segments (see Fig. 12B, C). If tagmosis is completely lacking, the segments proximal and distal to the elbow are subequal in width in length (Fig. 3D).

Heteromorphic sternal bars are differently shaped transverse bars on some trunk sternites. The male gonopores of the hermaphroditic remipedes are located on trunk segment 14 . In some taxa, the sternal bars on this segment are modified as enlarged, flap-like structures (see Fig. 8B). However, heteromorphy can also occur as a serial modification, e.g., sternal bars 1-14 can have a concave distal margin, while those on the posterior trunk are convex.

Isomorphic sternal bars are typically sublinear (with parallel margins) and subequal, thus, not modified on trunk segment 14 or any other trunk segment (see Fig. 11D).

\section{Systematics}

In the following sections, we provide an outline of the taxonomic structure of the class Remipedia. Although we consider the inclusion of higher taxa important for revised diagnoses of lower categories (in this case Speleonectes), diagnoses are omitted for taxa if they are not relevant for our comparisons. See Remarks for additional information.

Trunk segments are counted beginning at the first post-cephalic segment (not including maxillipeds). Segments of appendages are numbered from proximal to distal.

\section{Class Remipedia Yager, 1981}

Remipedia Yager, 1981: 328. Schram, Yager \& Emerson, 1986: 6 .

Diagnosis. - Hermaphroditic crustaceans with 6 segmented cephalon (including maxillipeds), head shield present. Trunk lacking tagmosis, composed of at least 15 segments; carapace absent; female gonopores on trunk segment 7 , male gonopores on trunk segment 14 . Antennules and antennae biramous. Labrum well developed. Post-oral cephalic appendages modified as subequal, uniramous, prehensile, raptorial mouthparts. Transverse sternal bars present. Trunk limbs as biramous, paddleshaped swimming appendages.

Remarks. - The class Remipedia includes two orders, the Nectiopoda Schram, 1986, and the Enantiopoda Birshtein, 1960. The latter order contains the fossils Tesnusocaris goldichi Brooks, 1955, and Cryptocaris hootchii Schram, 1974, as subordinate taxa.

\section{Order Nectiopoda Schram, 1986}

Nectiopoda Schram, 1986: 36. Schram, Yager \& Emerson, 1986: 6.

Diagnosis. - Cephalon with bifurcate, pre-antennular ventral filaments. Antennular peduncle fused, with long, filamentary aesthetascs. Antennae small, paddle-like; endopod 3-segmented, bent or as semicircular arc; exopod 1-segmented paddle. Mandibles lacking palps. Maxillules with 6-7 segments; terminal segment developed as fang-like claw, with a single pore at the tip. Maxillae and maxillipeds subequal; terminal segments developed as complex claws equipped with a cluster or arc of denticles typically opposed by a thumb-like pad bearing a row of filamentary, flexible setae. Maxillae with three lobate endites on basal segment. Maxillipeds 9-segmented, with 5 segments distal to elbow; endites of basal segments reduced, pad-like. Trunk limbs with 3-segmented exopod; endopod 4-segmented, basal segment reduced; anterior and posterior trunk limbs more slender than those of midtrunk, armature more reduced. Anal segment with simple caudal rami.

Remarks. - The Nectiopoda include two families, the Godzilliidae Schram, Yager \& Emerson, 1986, and the Speleonectidae Yager, 1981. The maxillipeds of a number of nectiopods are described as being composed of 8 segments. However, a reinvestigation of collection and type material did not confirm this. Maxillipeds appeared to be 9-segmented in all specimens evaluated, although some taxa in both families, Speleonectidae and Godzilliidae, show a tendency to reduce the size and articulation of the basal segments.

Family Speleonectidae Yager, 1981

Speleonectidae Yager, 1981: 328. Schram, Yager \& Emerson, 1986: 6.

Morlockiidae Garcia-Valdecasas, 1984: 329.

Type genus. - Speleonectes Yager, 1981.

Diagnosis. - Head shield subrectangular, often slightly tapered anteriorly. Transverse sternal bars of trunk isomorphic or heteromorphic. Ventral ra- 
mus of antennules well developed, typically with $7-15$ segments. Mandibles asymmetrical. Maxillules 7-segmented, with main point of flexure between segments 3 and 4; segment 2 with large lobate endite, equipped with distoanterior row of spines and distoposterior row of setae; endite of segment 3 well developed, but shorter than endites 1 and 2; medial margin of segment 4 expanded. Maxillae 7segmented; segments distal to elbow subequal to that of maxillipeds, but shorter; main point of flexure between segments 3 and 4. Maxillary and maxillipedal segments distal to elbow typically distinctly longer than segment proximal to elbow.

Remarks. - The family Speleonectidae is composed of the three genera Cryptocorynetes Yager, 1987a, Lasionectes Yager \& Schram, 1986, and Speleonectes Yager, 1981.

Genus Speleonectes Yager, 1981

Speleonectes Yager, 1981: 328; 1994: 752. Schram, Yager

\& Emerson, 1986: 6.

Morlockia Garcia-Valdecasas, 1984: 329.

Type species. - Speleonectes lucayensis Yager, 1981.

Diagnosis. - Maxillules typically more robust than maxillae and maxillipeds; endite of segment 3 bearing 2 prominent apical spines and several setae. Tagmosis of maxillae and maxillipeds weakly developed; setation of segment proximal to elbow and those distal to elbow composed of long and short setae or spines, sparsely distributed, not covering more than about $75 \%$ of medial margins; terminal claws as complex, horseshoe-shaped scrapers equipped with an arc of small, serrate denticles accompanied by 1 or 2 prominent, separate denticles.

Remarks. - The discovery of three new species of remipedes described herein reveals a number of inconsistencies concerning the diagnoses of the family Speleonectidae and the genera Speleonectes and Lasionectes. In particular, the tagmosis and setation of the three prehensile cephalic limbs needs to be redefined for both genera. A comprehensive revision of Remipedia is in preparation by one of us (SK), which will address these inconsistencies in greater detail.
Speleonectes tanumekes new species Figs. 1-3; Pl. 1

Type locality. - Basil Minns Blue Hole, Great Exuma Island, Exuma Cays, The Bahamas $\left(23^{\circ} 28^{\prime} \mathrm{N}, 75^{\circ}\right.$ $45^{\prime} \mathrm{W}$ ); collected in 33-43 $\mathrm{m}$ depth of anchihaline cave.

Material examined. - Holotype $(27 \mathrm{~mm}, 40$ trunk segments; ZMA Rem.204.577), 1 paratype (20 mm, 38 trunk segments; ZMA Rem.204.574), 10 paratypes (up to $26 \mathrm{~mm}$ and 40 trunk segments; JvdH 12-01 A1-3); all specimens were collected from the type locality by B. Kakuk and T. Iliffe, 12 Jan. 2003. The holotype (whole specimen) and 1 paratype (dissected) are preserved in alcohol. The remaining paratypes are preserved in formalin and will be retained in the research collection of the first author $(\mathrm{JvdH})$. Some of the paratypes are prepared for SEM investigations.

Etymology. - The epithet tanumekes (Greek for 'long-stretched') refers to the long and slender appearance of this species.

Diagnosis. - Long and slender species, up to 27 $\mathrm{mm}$, largest specimens composed of 38-40 trunk segments (Fig. 1A); pleural tergites weakly developed, with broadly rounded lateral margins in anterior part of trunk, becoming slightly pointed posteriorly; sternal bars sublinear, isomorphic; frontal filaments with short processes; dorsal flagella of antennules short; segment 4 of maxillule subrectangular, with small enditic lobe bearing 2 long, rasp-like spines and several slender setae; maxilla and maxilliped without distinct tagmosis, bearing few clusters of long, marginal setae; horseshoe-type claws of maxilla and maxilliped with 17-20 small denticles; anal somite slightly wider than long; caudal rami slightly longer than anal somite.

Description. - Body distinctly elongate and slender, with a maximum length of $27 \mathrm{~mm}$ and up to 40 trunk segments (Fig. 1A). Pleural tergites narrow, with broadly rounded distolateral corners on trunk segments $1-16$, becoming slightly acuminate in posterior part of trunk. Sternal bars sublinear and isomorphic. Female gonopores on trunk seg- 

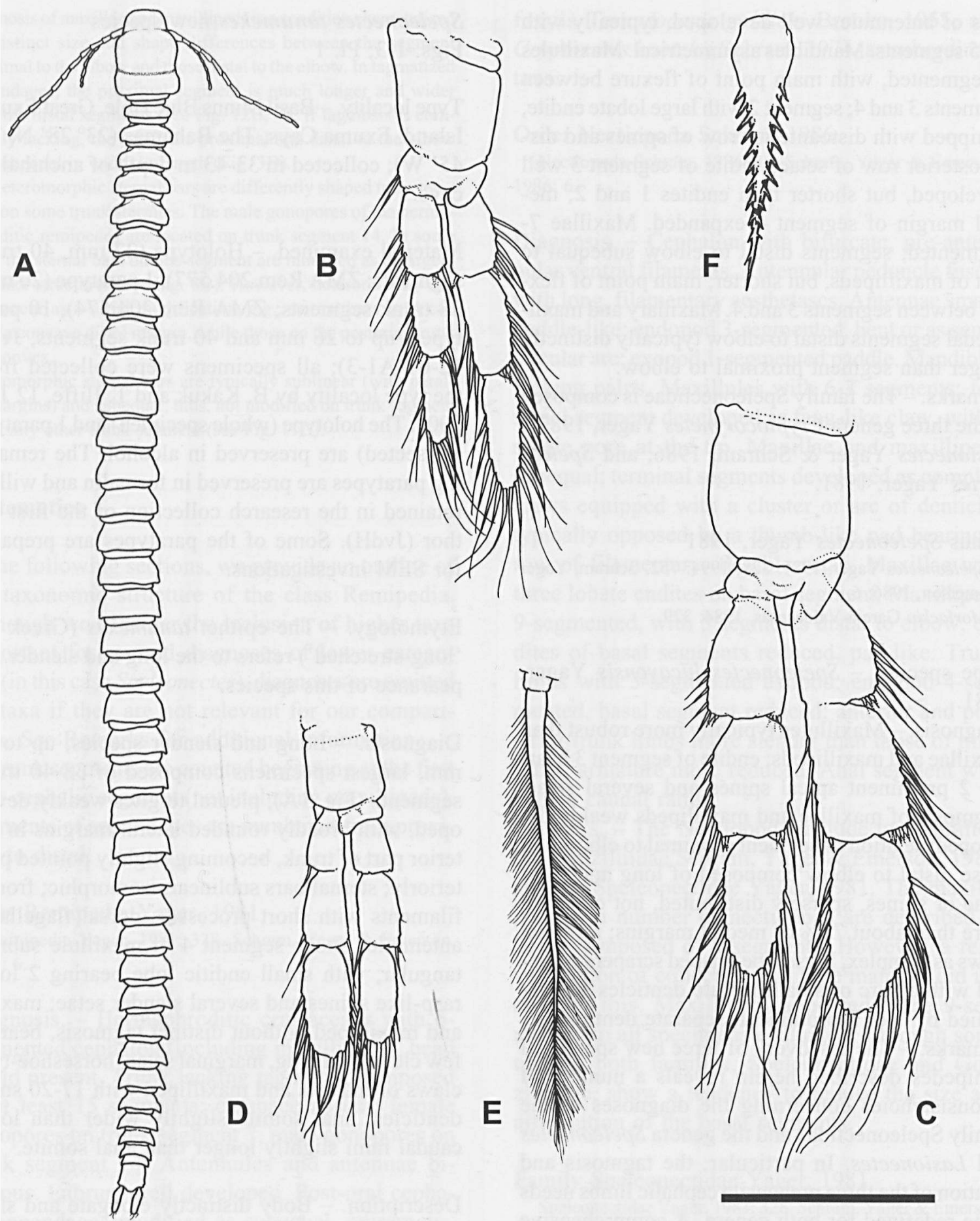

Fig. 1. Speleonectes tanumekes $\mathrm{n}$. sp.; A, $24 \mathrm{~mm}$ paratype; B-F, $20 \mathrm{~mm}$ paratype. B, first thoracopod; C, seventh thoracopod; D, 34th thoracopod; E, feathered seta; F, serrate spine. Scale bar $=0.5 \mathrm{~mm}$, for B-D. 

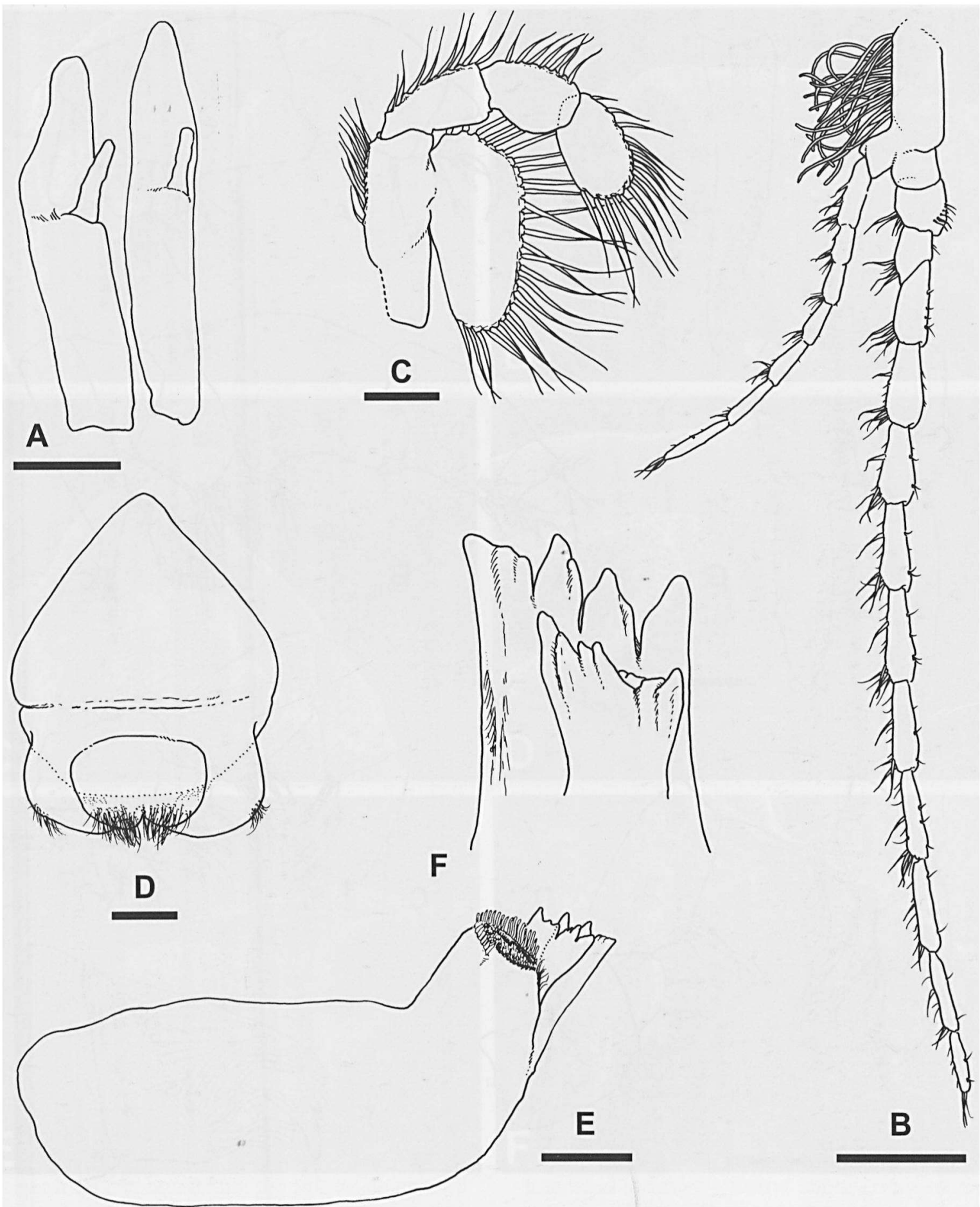

Fig. 2. Speleonectes tanumekes n. sp.; A, $24 \mathrm{~mm}$ paratype; B-F, $20 \mathrm{~mm}$ paratype. A, frontal filaments (scale bar $=0.1 \mathrm{~mm}$ ); B, antennule (scale bar $=0.5 \mathrm{~mm}$ ); C, antenna (scale bar $=0.1 \mathrm{~mm}$ ); D, labrum (scale bar $=0.1 \mathrm{~mm}$ ); E, right mandible (scale bar $=0.1$ $\mathrm{mm}$ ); F, enlarged lacinia mobilis and incisor process of left mandible. 


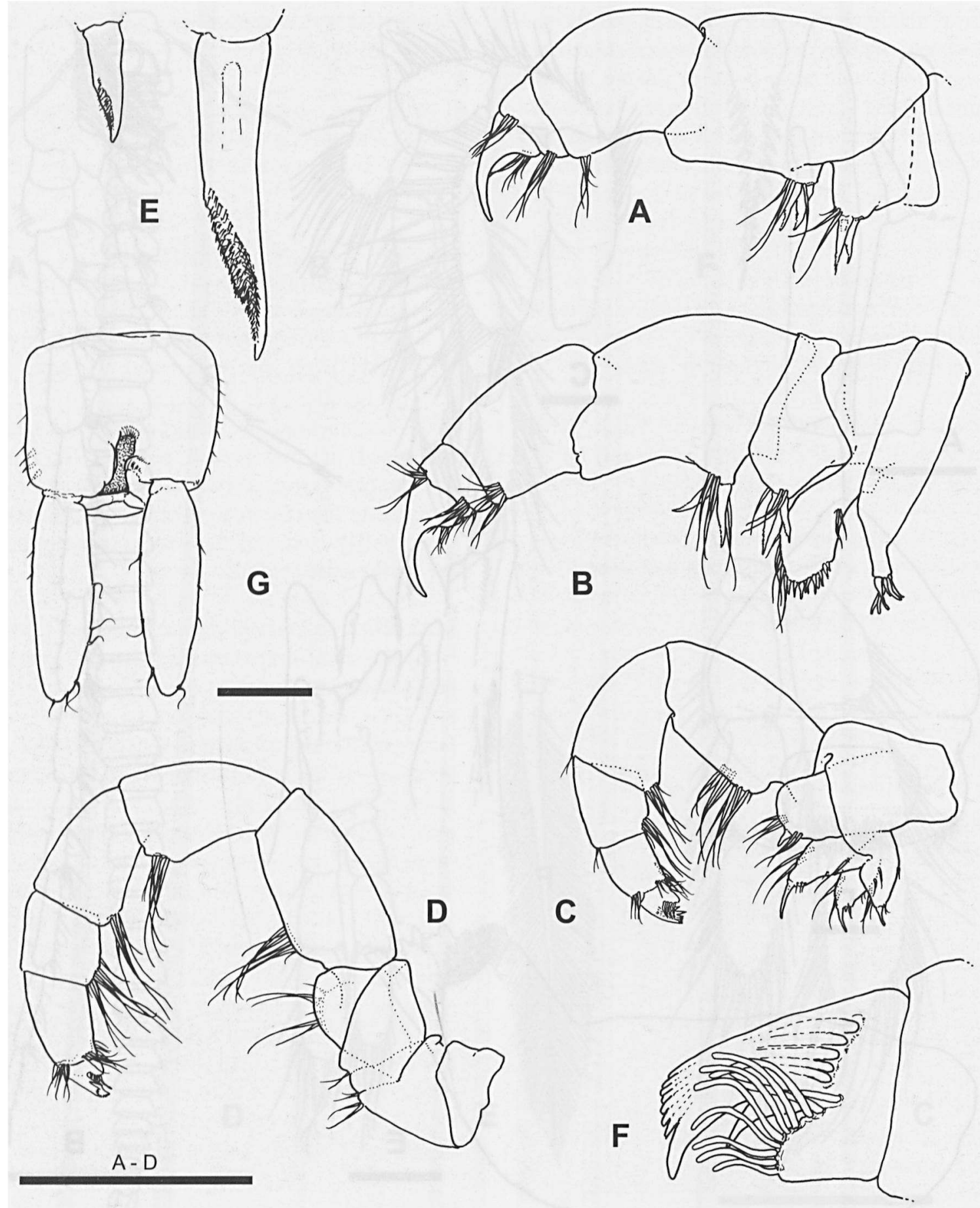

Fig. 3. Speleonectes tanumekes n. sp.; $20 \mathrm{~mm}$ paratype. A, right maxillule; B, left maxillule; C, maxilla; D, maxilliped; E, rasp-like spines of segment 2 (small spine), and segments 3-4 (large spine) of maxillule; F, claw of maxillae and maxillipeds; $\mathrm{G}$, anal segment and caudal rami (scale bar $=0.25 \mathrm{~mm}$ ). Scale bar A-D $=0.5 \mathrm{~mm}$. 

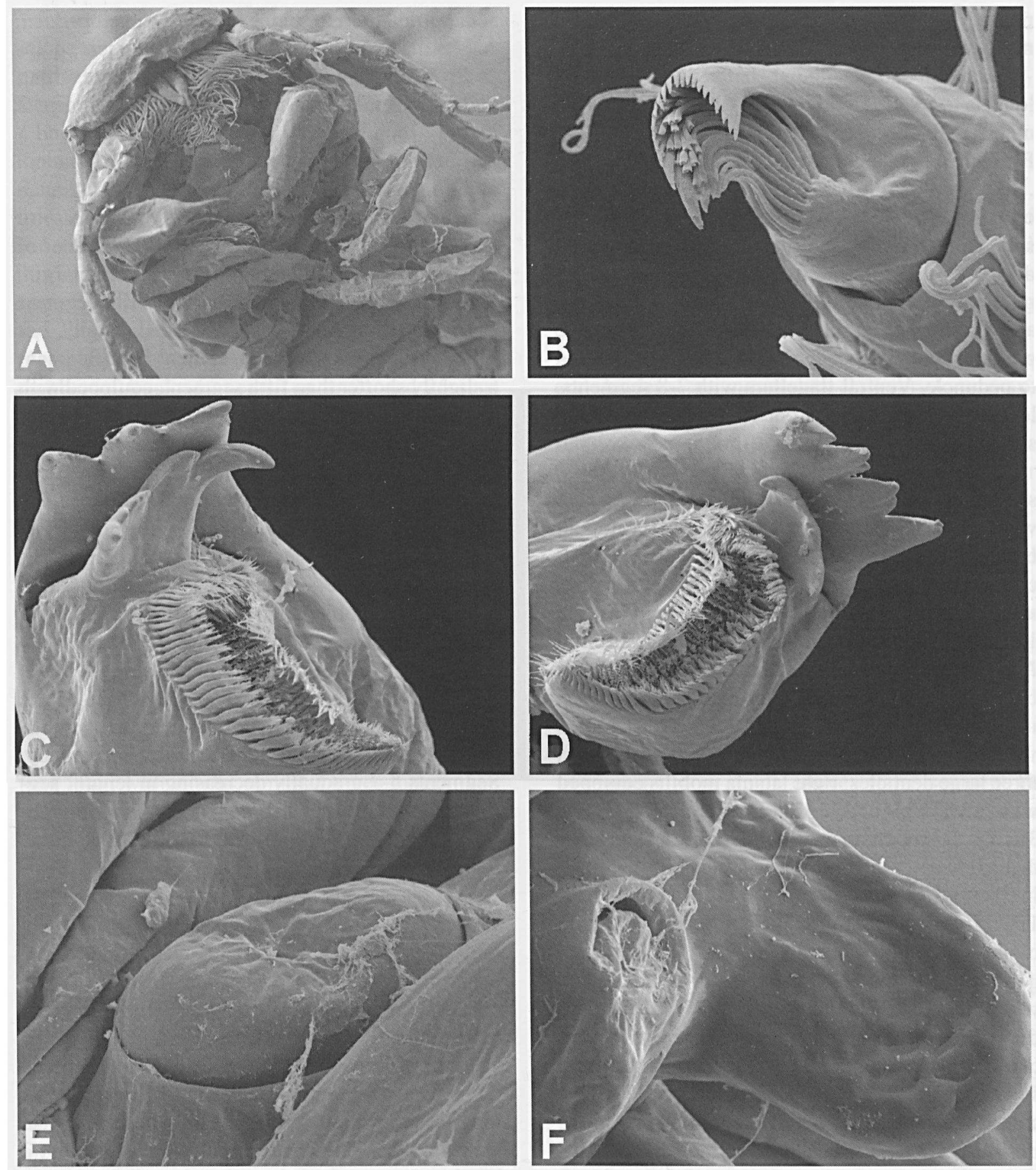

Pl. 1. Speleonectes tanumekes $\mathrm{n}$. sp., paratype. A, ventral view of head (60x); B, claw of maxilla (850x); C, detail of right mandible (500x); D, detail of left mandible (500x); E, female gonopore (1000x); F, male gonopore (1200x). 
ment 7 with tiny, triangular projections (Pl. 1E); male gonopores with ovate, rounded lobes $(\mathrm{Pl} .1 \mathrm{~F})$.

Cephalon subrectangular, tapered anteriorly, as long as trunk segments 1-4 (Fig. 1A). Frontal filaments with short mid-medial processes (Fig. 2A; Pl. 1A).

Antennules (Figs. 1A, 2B): Peduncle composed of at least 2 fused segments; proximal component subrectangular (barely dilated ventrally) bearing dense rows of long aesthetascs. Dorsal flagellum relatively short, about twice as long as head shield and $7 \%$ of length of body; with up to 13 segments; proximal-most segment apparently partially fused to peduncle. Ventral flagellum with 7-8 segments, less than half as long as dorsal flagellum, slightly shorter than head shield.

Antennae (Fig. 2C): Protopod 2-segmented, distal segment with row of 7-8 setae. Exopod longer and wider than adjacent distal segment of protopod, bearing 26-28 long setae. Endopod bent in a semicircular way; first two proximal segments with 8 and 7 setae, respectively; distal segment with 15 17 setae arranged in two rows (11-12+4-5 setae). All setae faintly feathered (see Fig. 1E).

Labrum fleshy, with posterolateral lobes bearing several clusters of fine setules (Fig. 2D).

Mandibles (Fig. 2E, F): Right incisor process with three large denticles; right lacinia mobilis equipped with three larger and several smaller denticles (Fig. $3 \mathrm{E} ; \mathrm{Pl}$. 1C). Left incisor process with four large denticles; left lacinia mobilis crescent-shaped, bearing several large and small denticles (Fig. 3F; Pl. 1D). Molar processes prominent; distal surface long, ovoid.

Maxillules (Fig. 3A, B): First segment equipped with long, narrow endite bearing 6-7 naked, slender spines distally. Endite of segment 2 broad, spatulate, with 5 setae along distoanterior margin, and 10 short spines on distoposterior margin; all short spines naked except 1 rasp-like spine (Fig. 3E), inserted anteriorly adjacent to row of setae. Third segment short, endite broadly rounded, bearing 2 long, slender, rasp-like spines (Fig. 3E), and a few setae. Segment 4 subrectangular, enditic lobe small, with 2 long, slender, rasp-like spines, and a few setae. Segment 5 slightly shorter and narrower than fourth segment, with a row of distomedial setae. Sixth segment very short, bearing separate rows of setae on distal margins. Claw well developed.

Maxillae (Fig. 3C): Endites of first segment equipped with 1 apical spine accompanied by a few long and short setae, respectively. Endite of segment 2 broadly rounded, with a single, short spine and a few setae. Third segment with weakly expanded, straight inner margin bearing 2 rows of about 8 long and 2 short setae. Segment 4 shorter than third segment; distal margin expanded, with a cluster of ca. 4 long setae and 1 short seta on inner margin, and 2 short setae on dorsal margin. Fifth segment shorter than segment 4 , not expanded distally, but setation subequal to that of segment four. Segment 6 slightly shorter than fifth segment, equipped with separate clusters of setae distally, and a few longer setae on midmedial margin. Arc of horseshoe-type claw finely serrate, composed of 17-20 fine denticles flanked by 2 stouter, separate denticles (P1. 1B; Fig. 3F).

Maxillipeds long, slender, 9-segmented (Fig. 3D); elbow between segments 4 and 5. Proximal segments 1-3 with oblique, interconnected articulation; segments 1 and 2 bearing a few short medial setae; segment 3 broadly rounded medially, with about 6-7 long and 2 short setae. Fourth segment with weakly expanded, straight ventral margin equipped with some 8-7 long and 2 short setae proximally. Segments 5-7 gradually decreasing in length; segment 5 slightly shorter than segment 4 , distal margin weakly expanded, with a medial cluster of about 6 long and short setae. Segment 6 bearing a distomedial cluster of 8 short and long setae. Segment 7 equipped with 9-12 short and long setae along mid- to distomedial margin. Segment 8 longer than segment 7 , with several separate clusters of setae on distal and distomedial margins. Claw subequal to that of maxillae (P1. 1B; Fig. 3F).

Trunk appendages (Fig. 1B-D; description based on larger thoracopods): Segment 1 of exopod with long setae on lateral margin, and about 3 serrate spines on distolateral corner (Fig. 1C); segment 2 bearing setae on both lateral and medial margins, and serrate spines on both distolateral and -medial corners; segment 3 ovate, with long, marginal setae. Endopod slightly shorter than exopod, but similar in shape and setation. All setae faintly feathered (Fig. 1E).

Anal segment slightly wider than long, lateral 
margins bearing a few short setae and spines (Fig $3 \mathrm{G}$ ); caudal rami 1.1-1.2 times longer than anal somite, with a few curling setae on medial and apical margins, respectively.

Remarks. - Speleonectes tanumekes has the largest number of trunk segments recorded for remipedes to date. The large number of segments, in combination with weakly developed pleurotergites, gives this species a rather elongate and slender appearance. Both S. epilimnius Yager \& Carpenter, 1999, and $S$. gironensis Yager, 1994, also have narrow pleurotergites, but are characterized by a smaller number of trunk segments (up to 21 and $25 \mathrm{seg}$ ments, respectively). In addition, $S$. tanumekes can be clearly distinguished from $S$. gironensis by differing shapes and setations of maxillules, maxillae and maxillipeds. Speleonectes tanumekes seems morphologically similar to $S$. epilimnius, but differs from the latter species by having a 13-segmented dorsal antennular flagellum (10-11 segments in $S$. epilimnius); a relatively large antennal exopod; longer and more slender spines on maxillulary segments 3 and 4; less expanded, straight margins of segments 3 and 4 (proximal to elbow) of maxillae and maxillipeds, respectively (more expanded and rounded in S. epilimnius); and an anal segment wider than long, with caudal rami 1.2 times longer than the anal somite (anal somite longer than wide, with caudal rami 2-2.5 times longer in S. epilimnius).

\section{Speleonectes parabenjamini new species}

Figs. 4-8; P1. 2

Type locality: Basil Minns Blue Hole, Great Exuma Island, Exuma Cays, The Bahamas $\left(23^{\circ} 28^{\prime} \mathrm{N}, 75^{\circ}\right.$ $45^{\circ} \mathrm{W}$ ); collected in $33-43 \mathrm{~m}$ depth of anchihaline cave.

Material examined: Holotype ( $9 \mathrm{~mm}, 22$ trunk segments; ZMA Rem.204.579) and 1 paratype (13 mm, 24 trunk segments; JvdH 12-01 A1); collected by B. Kakuk and T. Iliffe, 12 Jan. 2003. The holotype is dissected and preserved in alcohol. The paratype is prepared for SEM investigations and will be retained in the research collection of the first author (JvdH).
Etymology. - The specific epithet parabenjamini, meaning 'nearby benjamini', alludes to the morphological resemblance of this new species to Speleonectes benjamini.

Diagnosis. - A relatively small species (Fig. 4A); pleural tergites well developed, broadly rounded, becoming increasingly pointed in posterior part of trunk; trunk sternites with pointed posterolateral corners; sternal bars heteromorphic; frontal filaments with short, stout processes; antennules with long dorsal flagella; segment 4 of maxillule subrectangular, bearing 1 very long, serrate spine and several slender setae; maxillulary claw very long; maxilla and maxilliped slender, without distinct tagmosis, setation sparse; arc of horseshoe-type claw composed of 7-8 small denticles; anal somite longer than wide; caudal rami shorter than anal somite.

Description. - Body short, up to $13 \mathrm{~mm}$, composed of 24 postcephalic segments (Fig. 4A). Pleural tergites well developed, with broadly rounded distolateral corners on trunk segments 1-7, becoming increasingly acuminate posteriorly. Posterolateral corners of trunk sternites with distinctly pointed corners (Fig. 8B; Pl. 2C). Sternal bars heteromorphic, slightly concave on segments $1-13$, posterior to segment 14 as small, convex flaps; segment 14 with large convex flap (Pl. 2C). Male gonopores on trunk segment 14 with rounded lobes.

Cephalon subrectangular, with concave anterolateral excavations, as long as trunk segments 1-4 (Fig. 4A). Frontal filaments bearing short, corpulent, mid-medial processes (Fig. 5A).

- Antennules with long dorsal flagella, reaching up to $60 \%$ of length of body (Figs. 4A, 5B). Peduncle composed of at least 2 fused segments; ventral margin expanded, bearing densely inserted, long aesthetascs. Dorsal flagellum with 14 segments. Ventral flagellum with up to 15 segments, less than half as long as dorsal flagellum, but slightly longer than head shield.

Antennae (Fig. 5C): Protopod 2-segmented, proximal segment equipped with 7 marginal setae; distal segment with 11 setae. Exopod longer and wider than adjacent distal segment of protopod, bearing about 37 long setae. Endopod forming a semicircular arc; first two proximal segments with 6-8 setae, 


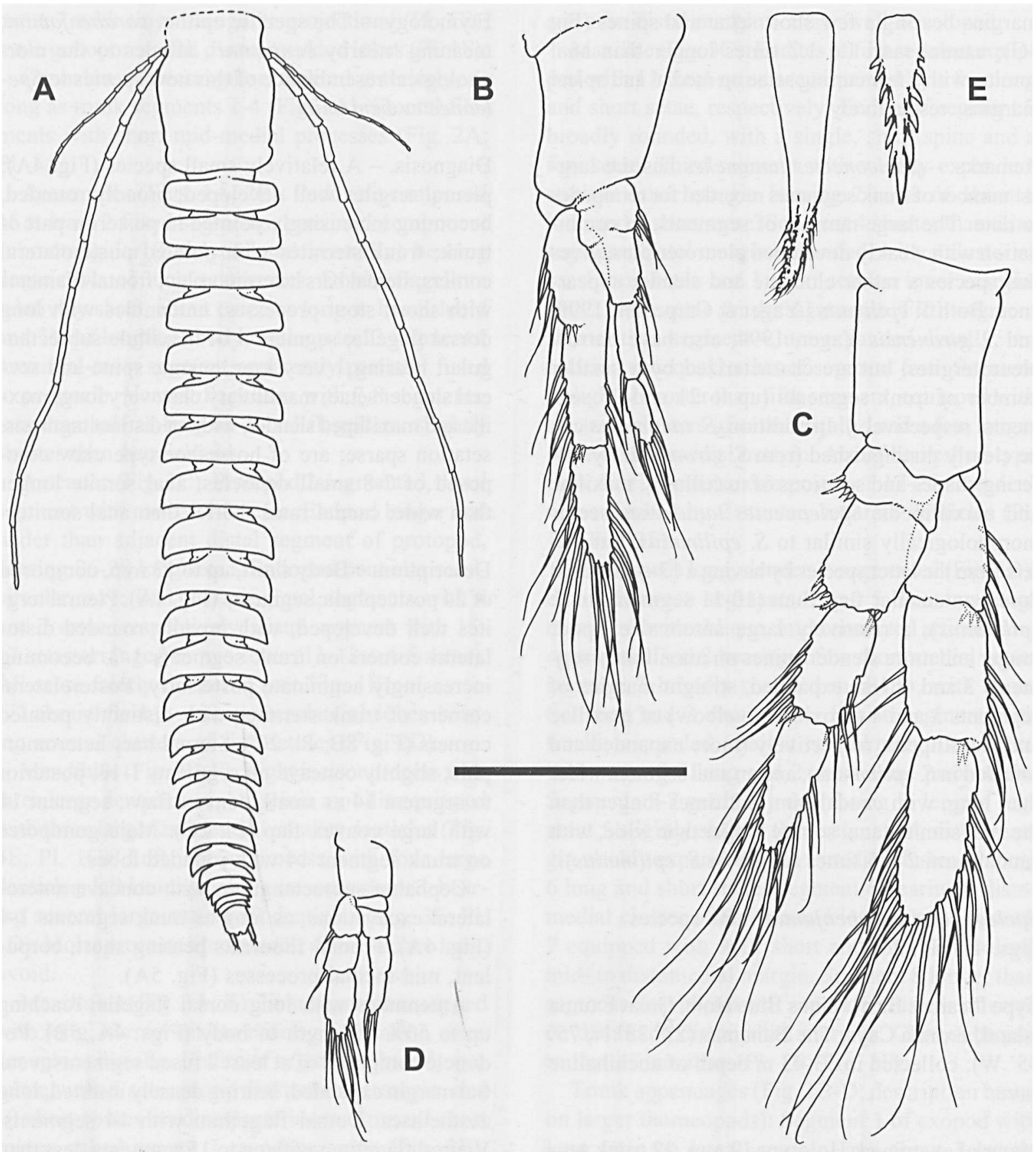

Fig. 4. Speleonectes parabenjamini $\mathrm{n}$. sp.; A, $13 \mathrm{~mm}$ paratype; B-E, $9 \mathrm{~mm}$ holotype. B, first thoracopod; C, seventh thoracopod; D, thoracopod of posterior trunk; E, rasp-like spine (left) and serrate spine (right). Scale bar $=0.5 \mathrm{~mm}$, for B-D. 


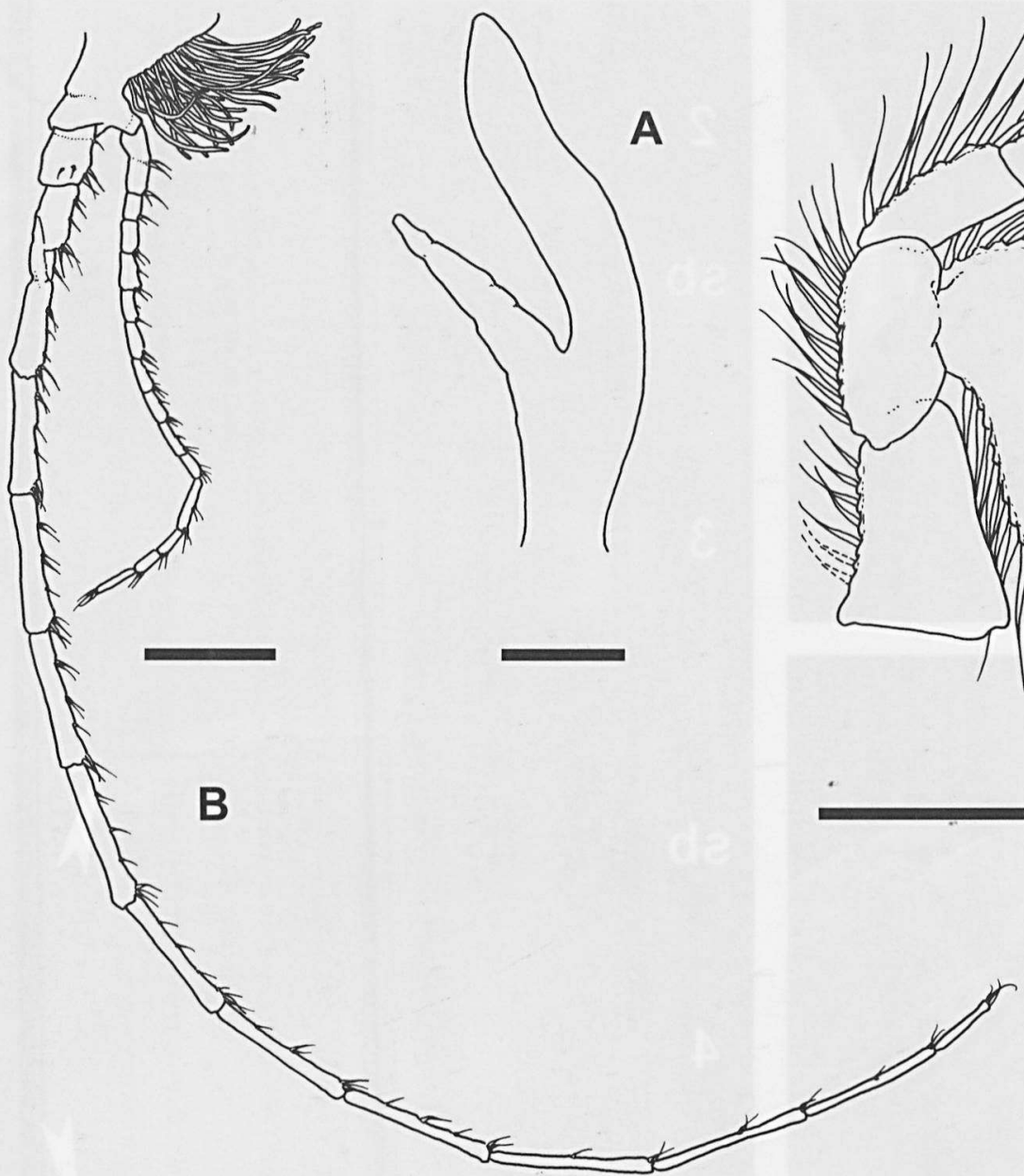

Fig. 5. Speleonectes parabenjamini n. sp.; A, $13 \mathrm{~mm}$ paratype; B-C, $9 \mathrm{~mm}$ holotype. A, frontal filament (scale bar $=0.1 \mathrm{~mm})$; $\mathrm{B}$, antennule (scale bar $=0.5 \mathrm{~mm}) ; \mathrm{C}$, antenna $($ scale bar $=0.5 \mathrm{~mm})$.

respectively; distal segment with up to 17 setae arranged in two rows. All setae faintly feathered (cf. Fig. 1E).

Labrum fleshy, with clusters of fine setules on posterior margin (Fig. 6A).

Mandibles (Fig. 6B, C; Pl. 2A): Right incisor process and lacinia mobilis with three large denticles; respectively. Left incisor process with four large denticles; left lacinia mobilis crescent-shaped, apical margin serrate. Molar processes prominent; distal surface long, ovoid.

Maxillules a little more robust than maxillae and maxillipeds (Fig. 7A, D-E). First segment equipped with long and narrow endite bearing 1 large, prominent spine and 5-6 small spines (all naked). Endite of segment 2 ovate, spatulate, with 4-5 long setae on distoanterior margin, and 8 short spines and 1 short seta on distoposterior margin (all short spines naked except 1 rasp-like spine at end of spine row; Fig. 7D). Third segment short, with conical endite, bearing 2 long, slender, rasp-like spines, and a few setae. Segment 4 subrectangular, medial margin even, bearing 1 very long, slender, rasp-like spine on proximal corner (Fig. 7E), and 7-9 long and short setae. Segment 5 as long as segment 4, but slightly narrower, with a cluster of distomedial setae. Sixth segment short, equipped with separate rows of long and shorter setae on distal margins. Claw very long.

Maxillae (Fig. 7B): First endite of first segment bearing 1 apical spine and a few setae; endites 2 

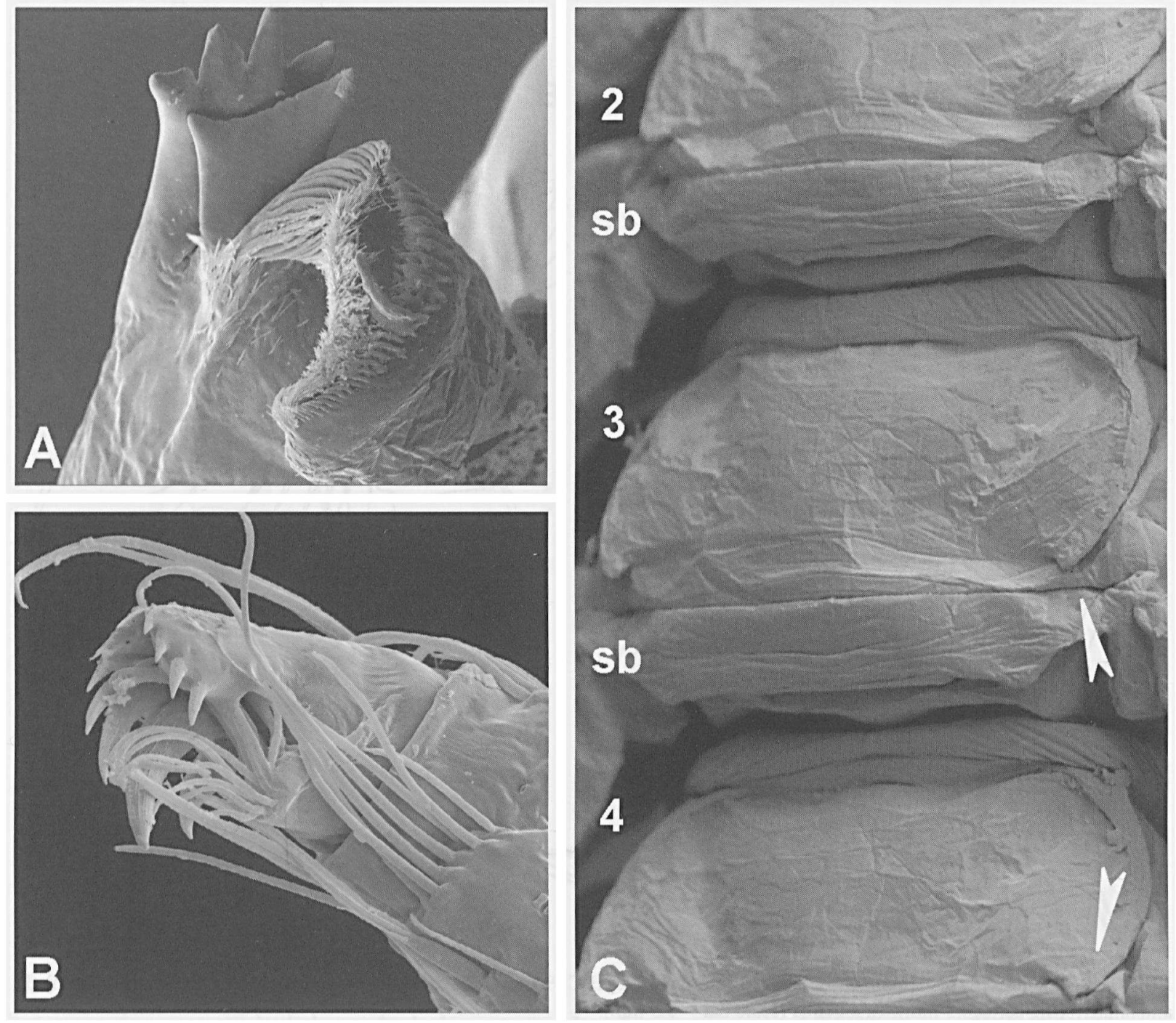

Pl. 2. Speleonectes parabenjamini $\mathrm{n}$. sp., paratype. A, detail of left mandible (500x); B, claw of maxilliped (1000x); C, trunk sternites and sternal bars $(\mathrm{sb})$ of trunk segments $2-4$ (pointed postę̧olateral corners indicated by arrows) (90x).

and 3 with 1 prominent, apical spine, 3 smaller subapical spines, and several setae. Endite of segment 2 equipped with a single, short spine and about 9 short and long setae. Third segment long, with barely expanded, straight medial margin bearing 10-12 long and short setae. Segment 4 shorter than segment 3; distomedial margin with a row of $10-$ 12 setae. Fifth segment half as long as segment 4 , bearing about 6 setae on distomedial margin. Segment 6 distinctly longer than fifth segment, with 4 sparsely inserted setae along medial margin, and separate clusters of setae distally. Arc of horseshoetype claw composed of 7-8 small denticles flanked by 2 stronger, separate denticles (Fig. 7F).

Maxillipeds long, slender, 9-segmented (Fig. 7C); elbow between segments 4 and 5 . Segment 1 bearing a few short medial setae; segment 2 equipped with 2 slender medial spines; segment 3 rather long, with a cluster of distomedial long and short setae. Segment 4 very long and narrow, bearing a row of 7-8 midmedial setae. Segments 5-7 gradually decreasing in length; segment 5 a little shorter than segment 4 , distal margin expanded, with a cluster of distomedial setae. Segments 6-8 bearing rows of setae on mid- and distomedial margins, respectively. Segment 8 distinctly longer than segment 


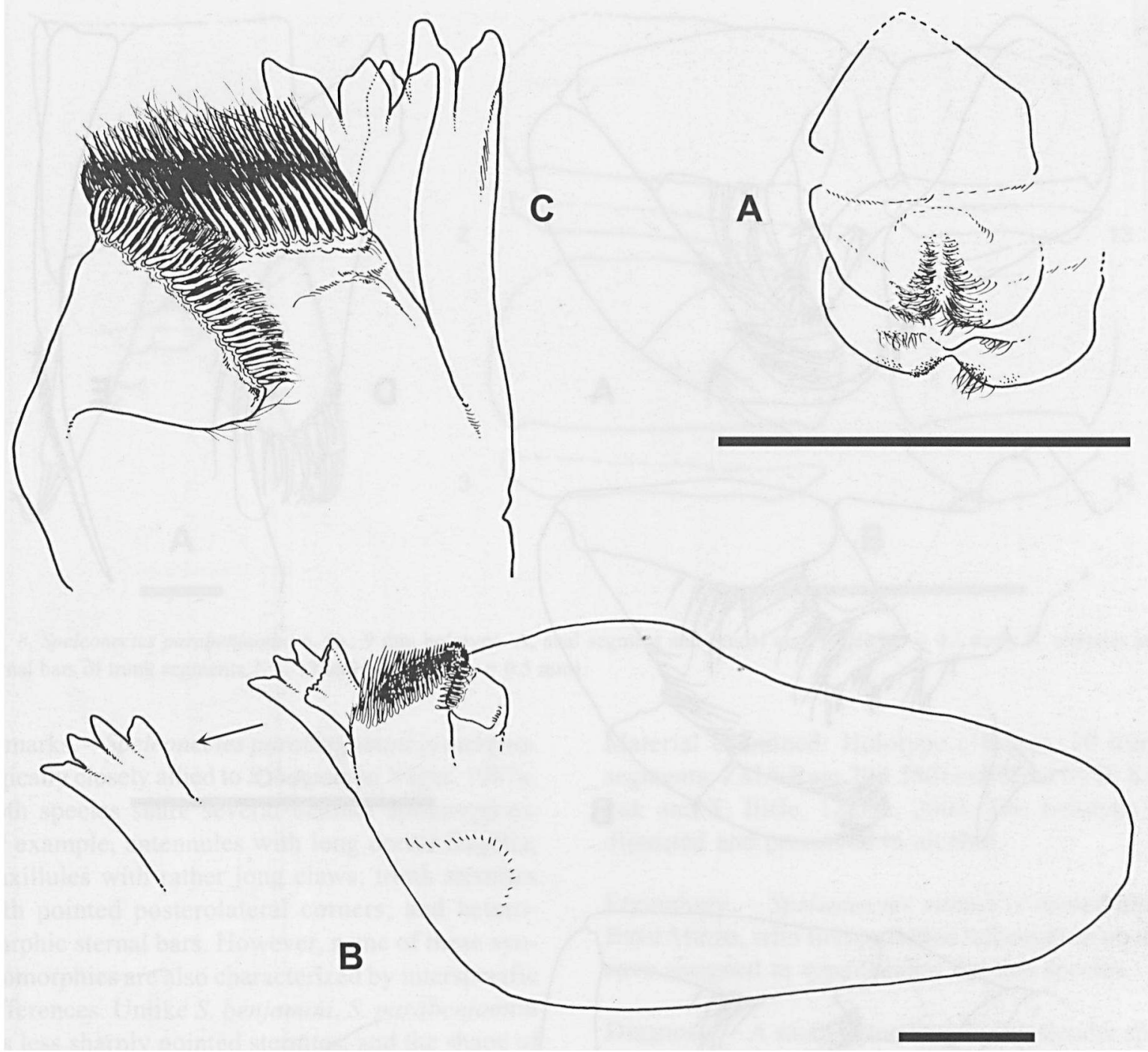

Fig. 6. Speleonectes parabenjamini n. sp.; 9 mm holotype. A, labrum (partly damaged; scale bar $=0.5 \mathrm{~mm}$ ); B, left mandible, with slightly enlarged incisor process (scale bar $=0.1 \mathrm{~mm}$ ); , enlarged detail of right mandible. Please note that the angled appearance of the molar processes is an artefact caused by preservation.

7, with several separate clusters of setae on distal margins. Claws subequal to those of maxillae (Fig. 7F; Pl. 2B).

Trunk appendages (Fig. 4B-D): Segment 1 of exopod equipped with long setae on lateral margin, and about 3 serrate spines on distolateral corner (Fig. 4C, E); segment 2 with setae on both lateral and medial margins, and 2-4 serrate spines on distolateral corner; segment 3 ovate, bearing long marginal setae. Endopod slightly shorter and narrower than exopod; distribution of feathered setae similar to that of exopod, with the following exceptions: basal segment with 3-4 rasp-like, lateral spines (Fig. 4E); distolateral corner of segment 2 bearing 4 rasp-like spines and 1 strongly serrate spine, distomedial corner with 2 serrate spines; segment 3 with 2 serrate spines on distolateral corner and 1 serrate spine on distomedial corner. Endopods of anterior and posterior trunk limbs comparatively strongly reduced. All setae faintly feathered (cf. Fig. 1E).

Anal segment longer than wide (Fig 8A); length of caudal rami about $66 \%$ of length anal somite; caudal rami bearing 1-2 curling setae on midmedial margins up to 6 curling apical setae, respectively. 

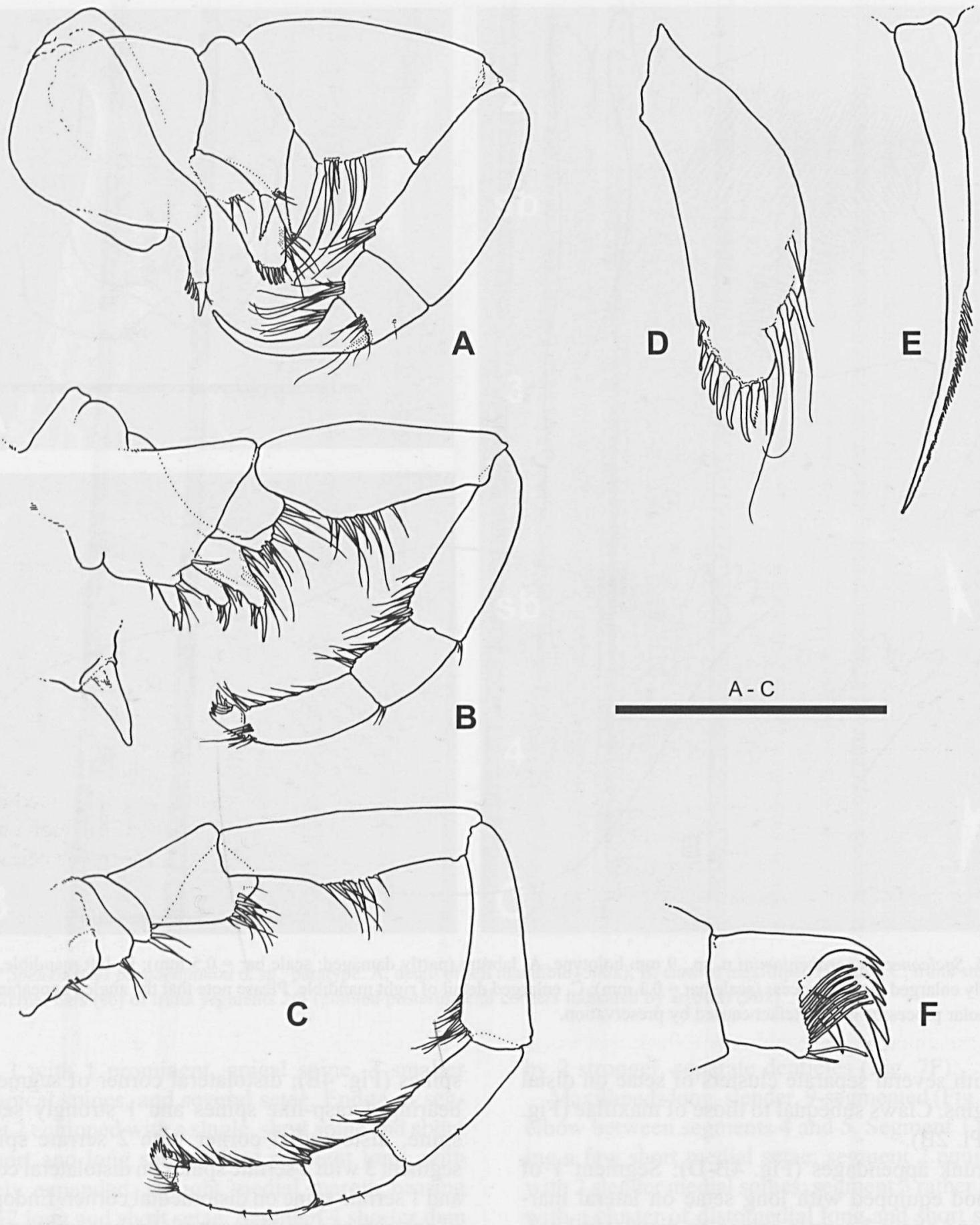

Fig. 7. Speleonectes parabenjamini n. sp.; 9 mm holotype. A, maxillule; B, maxilla, with enlarged spine of segment 2; C, maxilliped; $D$, enlarged maxillulary endite of segment 2 ; E, long rasp-like spine of maxillulary segment 4 ; F, claw of maxillae and maxillipeds. Scale bar $\mathrm{A}-\mathrm{C}=0.5 \mathrm{~mm}$. 


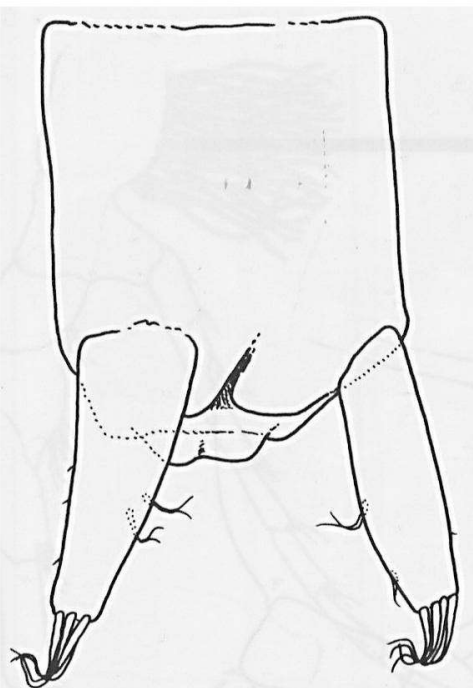

A

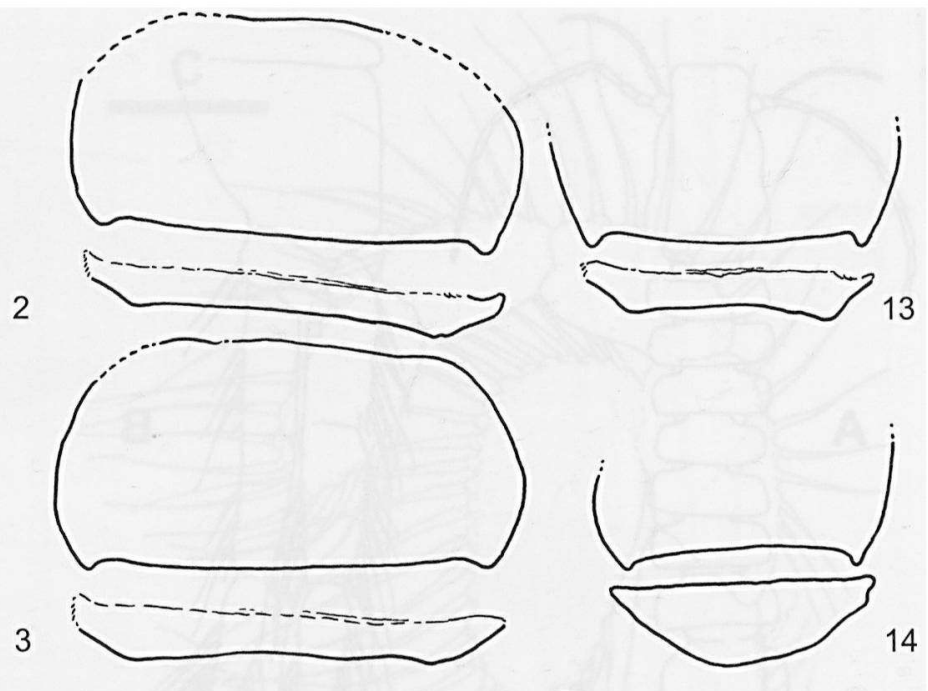

B

Fig. 8. Speleonectes parabenjamini $\mathrm{n}$. sp.; $9 \mathrm{~mm}$ holotype. A, anal segment and caudal rami (scale bar $=0.1 \mathrm{~mm}$ ); $\mathrm{B}$, sternites and sternal bars of trunk segments $2,3,13$ and 14 (scale bar $=0.5 \mathrm{~mm}$ ).

Remarks. - Speleonectes parabenjamini is morphologically closely allied to $S$. benjamini Yager, 1987a. Both species share several distinct apomorphies, for example, antennules with long dorsal flagella; maxillules with rather long claws; trunk sternites with pointed posterolateral corners; and heteromorphic sternal bars. However, some of these synapomorphies are also characterized by interspecific differences. Unlike $S$. benjamini, S. parabenjamini has less sharply pointed sternites, and the shape of the anterior sternal bars is only slightly concave. Furthermore, $S$. parabenjamini can be easily distinguished from $S$. benjamini by possessing ventral antennular flagella that lack a fusion of proximal segments; maxillules and maxillae that are more slender (less expanded), with much longer and slender segments proximal to the elbows; an anal segment that is longer than wide; and caudal rami shorter than the anal segment.

\section{Speleonectes minnsi new species}

Figs. 9-12

Type locality: Basil Minns Blue Hole, Great Exuma Island, Exuma Cays, The Bahamas $\left(23^{\circ} 28^{\prime} \mathrm{N}, 75^{\circ}\right.$ $45^{\prime} \mathrm{W}$ ); collected in $33-43 \mathrm{~m}$ depth of anchihaline cave.
Material examined: Holotype $(18 \mathrm{~mm}, 30$ trunk segments; ZMA Rem.204.580) collected by B. Kakuk and T. Iliffe, 12 Jan. 2003. The holotype is dissected and preserved in alcohol.

Etymology. - Speleonectes minnsi is named after Basil Minns, who first provided information on the cave assigned as type locality for this species.

Diagnosis. - A small to medium-sized, slender species (Fig. 9A); pleural tergites developed, broadly rounded, becoming angular in posterior part of trunk; sternal bars isomorphic; frontal filaments with long processes; antennules with short dorsal flagella; segment 4 of maxillule expanded; maxilla and maxilliped exhibiting tagmosis (see definitions of terms); arc of horseshoe-like claw composed of 7 small denticles; anal somite longer than wide; caudal rami shorter than anal somite.

Description. - Body slender, length $18 \mathrm{~mm}, 30$ trunk segments (Fig. 9A). First trunk segment much smaller than adjacent posterior segments. Pleural tergites developed, with broadly rounded distolateral corners on trunk segments 1-10, becoming angular to pointed posteriorly. Sternal bars sublinear, isomorphic (Fig. 11D). Male gonopores on trunk segment 14 with small triangular lobes. 


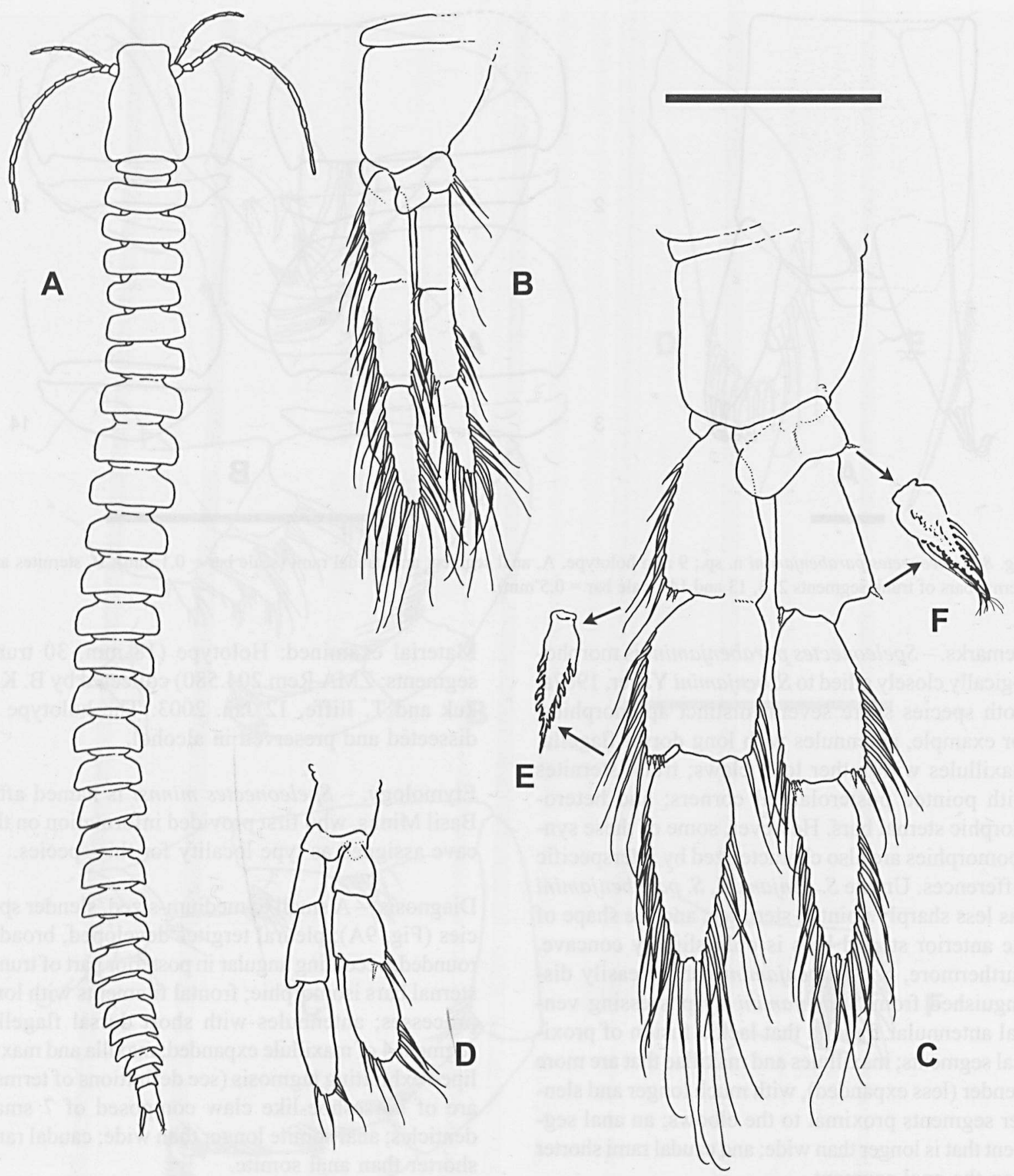

Fig. 9. Speleonectes minnsi n. sp,; $18 \mathrm{~mm}$ holotype. A, dorsal view of body; B, first thoracopod; C, seventh thoracopod; D, 27th thoracopod; E, serrate spine; F, setulose spine. Scale bar $=0.5 \mathrm{~mm}$, for B-D. 

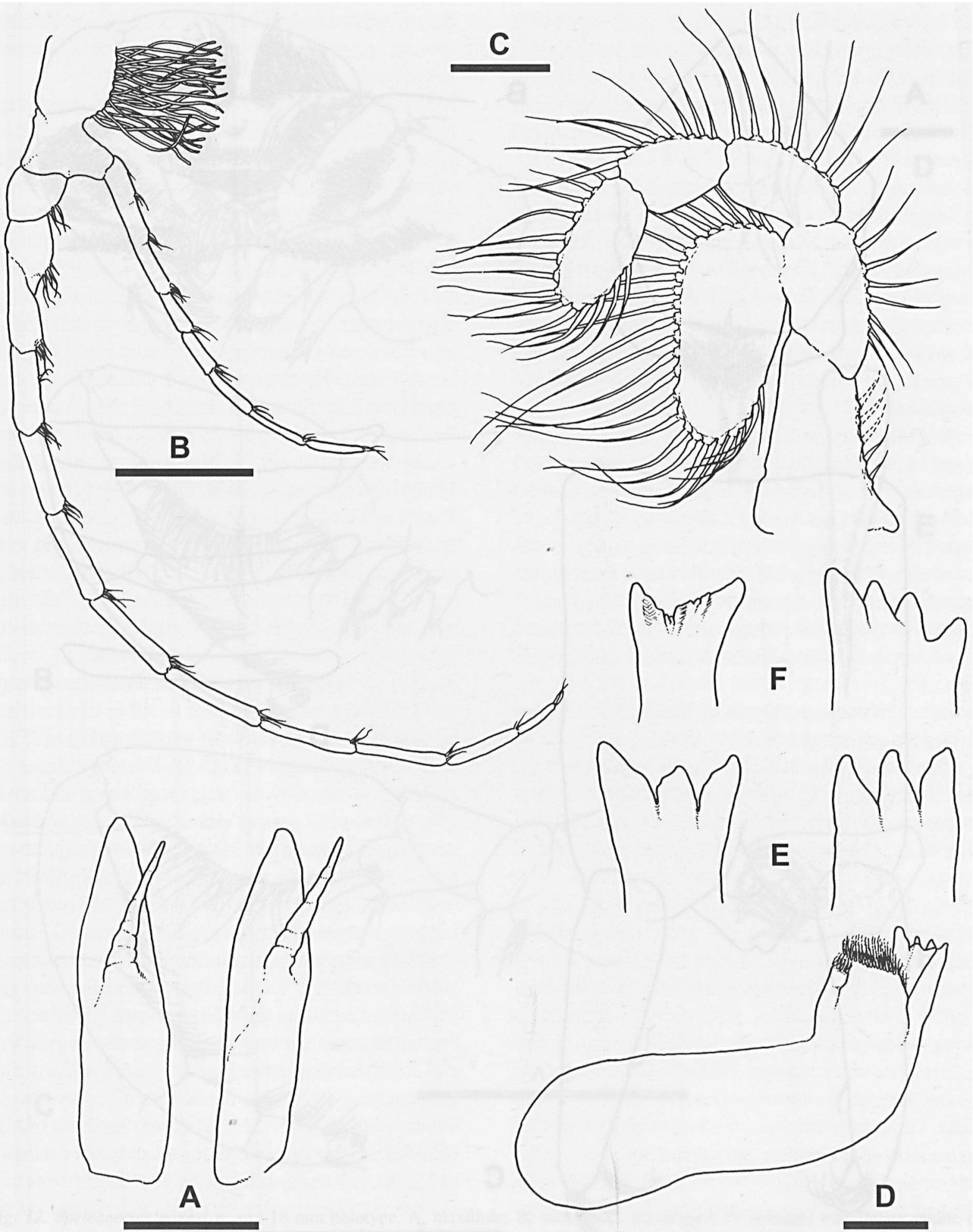

Fig. 10. Speleonectes minnsi $\mathrm{n}$. sp.; $18 \mathrm{~mm}$ holotype. A, frantal filaments (scale bar $=0.1 \mathrm{~mm}$ ); B, antennule (scale bar $=0.5 \mathrm{~mm}$ ); C, antenna (scale bar $=0.1 \mathrm{~mm}$ ); D, right mandible (scale bar $=0.1 \mathrm{~mm}$ ); E, enlarged lacinia mobilis (left) and incisor process (right) of right mandible; F, enlarged lacinia mobilis (left) and incisor process (right) of left mandible. 

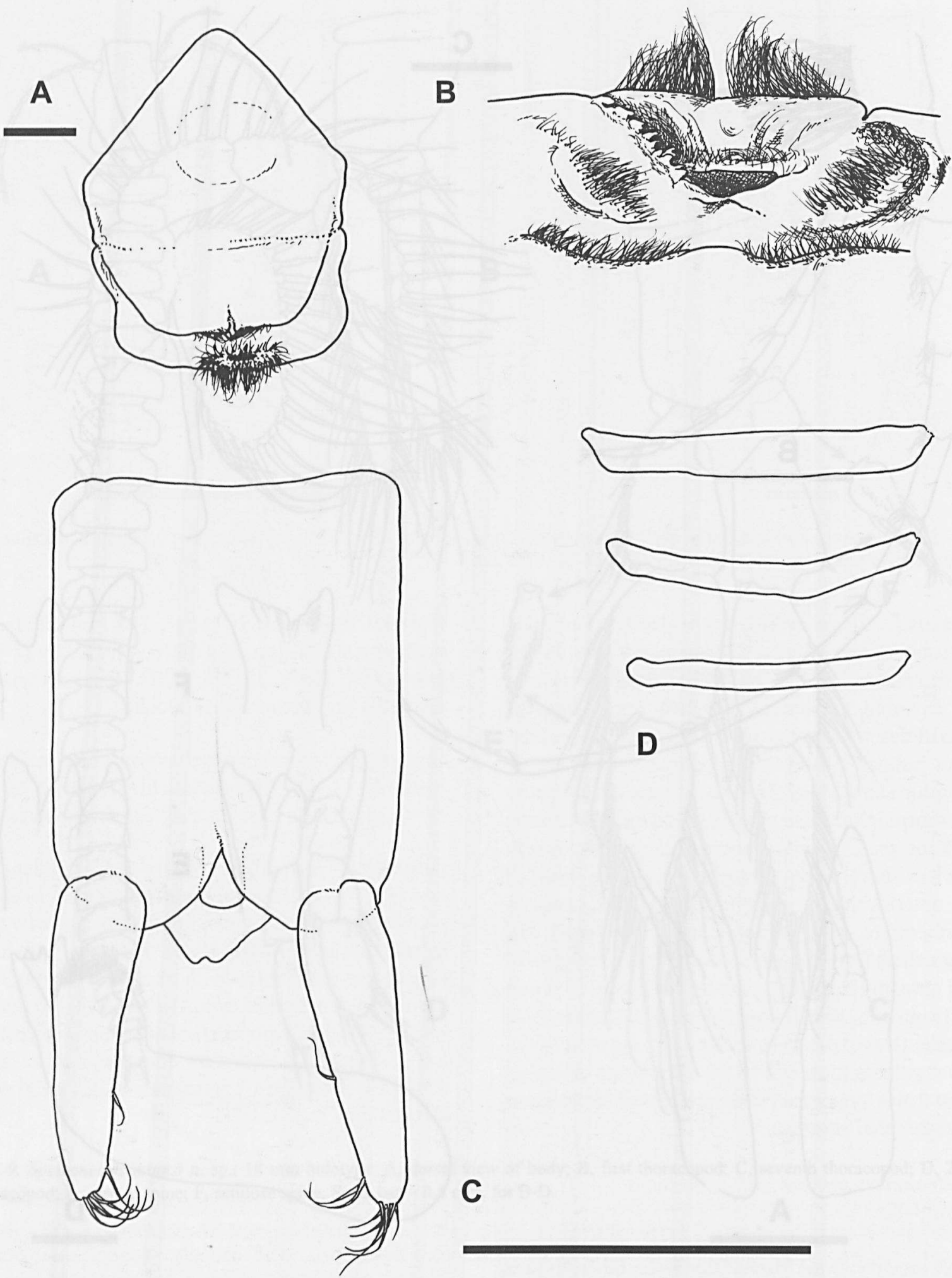

D

\section{C}

Fig. 11. Speleonectes minnsi n. sp.; $18 \mathrm{~mm}$ holotype. A, labrum (scale bar $=0.1 \mathrm{~mm}$ ); B, detail of apical margin of labrum; C; anal segment and caudal rami (scale bar $=0.5 \mathrm{~mm}$ ); D, sternal bars 4,13 and 18 (from top). 


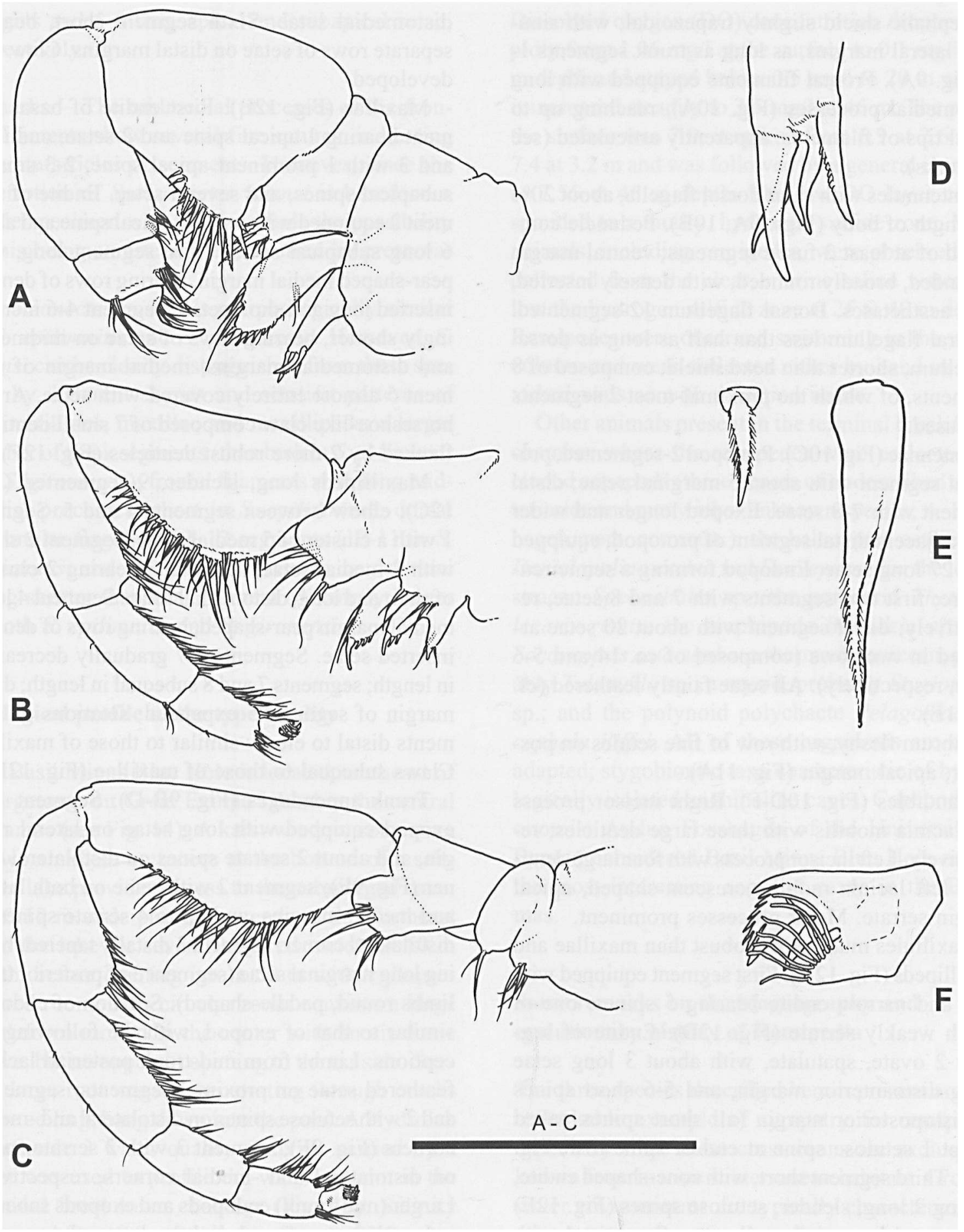

Fig. 12. Speleonectes minnsi $\mathrm{n}$. sp.; $18 \mathrm{~mm}$ holotype. A, maxillule; B, maxilla; C, maxilliped; D, enlarged maxillulary endite of segment 1; E, setulose spines of maxillulary segments 3 (left) and 4 (right); F, claw of maxillae and maxillipeds. Scale bar A-C $=0.5$ $\mathrm{mm}$. 
Cephalic shield slightly trapezoidal, with sinusoid lateral margins, as long as trunk segments 14 (Fig. 9A). Frontal filaments equipped with long mid-medial processes (Fig. 10A), reaching up to distal tips of filaments, apparently articulated (see Remarks).

Antennules with short dorsal flagella, about 20\% of length of body (Figs. 9A, 10B). Peduncle composed of at least 2 fused segments; ventral margin expanded, broadly rounded, with densely inserted, long aesthetascs. Dorsal flagellum 12-segmented. Ventral flagellum less than half as long as dorsal flagellum, shorter than head shield, composed of 8 segments, of which the proximal-most 2 segments are fused.

Antennae (Fig. 10C): Protopod 2-segmented, proximal segment with about 5 marginal setae; distal segment with 7-8 setae. Exopod longer and wider than adjacent distal segment of protopod, equipped with 27 long setae. Endopod forming a semicircular arc; first two segments with 7 and 8 setae, respectively; distal segment with about 20 setae arranged in two rows (composed of ca. 14 and 5-6 setae, respectively). All setae faintly feathered (cf. Fig. 1E).

Labrum fleshy, with row of fine setules on posterior, apical margin (Fig. 11A).

Mandibles (Fig. 10D-F). Right incisor process and lacinia mobilis with three large denticles; respectively. Left incisor process with four large denticles; left lacinia mobilis crescent-shaped, apical margin serrate. Molar processes prominent.

Maxillules much more robust than maxillae and maxillipeds (Fig. 12A). First segment equipped with long and narrow endite bearing 5 spines, ope of which weakly serrate (Fig. 12D). Endite of segment 2 ovate, spatulate, with about 3 long setae along distoanterior margin, and 5-6 short spines on distoposterior margin (all short spines naked except 1 setulose spine at end of spine row; Fig. 12E). Third segment short, with cone-shaped endite, bearing 2 long, slender, setulose spines (Fig. 12E) and several long and small setae. Segment 4 with obliquely expanded medial margin even bearing two rows of 8-9 short and long setae; proximal corner (endite) equipped with 3 setulose spines ( 2 of which long and slender and 1 rather short). Segment 5 as long as segment 4 , expanded, with a cluster of distomedial setae. Sixth segment short, bearing separate rows of setae on distal margins. Claw well developed.

Maxillae (Fig. 12B): First endite of basal segment bearing 1 apical spine and 2 setae; endites 2 and 3 with 1 prominent apical spine, 2-3 smaller subapical spines, and several setae. Endite of segment 2 equipped with a single apical spine and about 6 long subapical setae. Third segment long, with pear-shaped medial margin, bearing rows of densely inserted long and short setae. Segment 4-6 increasingly shorter, bearing rows of setae on midmedial and distomedial margins; medial margin of segment 5 almost entirely covered with setae. Arc of horseshoe-like claw composed of 7 small denticles flanked by 2 more robust denticles (Fig. 12F).

Maxillipeds long, slender, 9-segmented (Fig. 12C); elbow between segments 4 and 5. Segment 1 with a cluster of 5 medial setae; segment 2 short, with 2 medial setae; segment 3 bearing 2 clusters of short and long, distomedial setae. Segment 4 long, medial margin pear-shaped, bearing rows of densely inserted setae. Segments 5-7 gradually decreasing in length; segments 7 and 8 subequal in length; distal margin of segment 5 expanded; setations of segments distal to elbow similar to those of maxillae. Claws subequal to those of maxillae (Fig. 12F).

Trunk appendages (Fig. 9B-D): Segment 1 of exopod equipped with long setae on lateral margin, and about 2 serrate spines on distolateral corner (Fig. 9E); segment 2 with setae on both lateral and medial margins, and up to 4 serrate spines on distolateral corner; segment 3 distally tapered, bearing long marginal setae (segment 3 of posterior trunk limbs round, paddle-shaped). Setation of endopod similar to that of exopod, with the following exceptions: Limbs from mid-trunk posteriad lacking feathered setae on proximal segments; segment 1 and 2 with setulose spines on distolateral and -medial corners (Fig. 9F); segment 3 with 2 serrate spines on distolateral and -medial corners, respectively. Larger (mid-trunk) endopods and exopods subequal in length, but endopod slightly shorter than exopod on anterior and posterior trunk. All setae faintly feathered (cf. Fig. 1E).

Anal segment 1.3 times longer than wide (Fig $11 \mathrm{C})$; length of caudal rami about $69 \%$ of length anal somite, bearing a single, fine seta on midmedial 
margins and 5-6 fine, apical and subapical setae, respectively.

Remarks. - The midmedial processes of the frontal filaments show several fine sutures, indicating separate articles or segments. However, since the description of Speleonectes minnsi is based on a single specimen we cannot exclude the possibility of this being an artefact, e.g., caused by preservation.

Speleonectes minnsi is morphologically similar to $S$. epilimnius and $S$. gironensis. However, $S$. minnsi can be clearly distinguished from these species by different shapes and setation patterns of the maxillules, maxillae and maxillipeds; a larger number of trunk segments (than both in S. epilimnius and $S$. gironensis); frontal filaments with long midmedial processes (short in S. epilimnius); dorsal antennular flagella with 12 segments (10-11 in $S$. epilimnius, and 10 in $S$. gironensis); caudal rami being shorter than anal segment (distinctly longer in both $S$. epilimnius and $S$. gironensis).

\section{Ecological profile of the type locality}

The Basil Minns Blue Hole is located southeast of Georgetown on Great Exuma Island in the central Bahamas (see Fig. 14). A karst window consisting of two sinkhole entrances at the bottom of a saltwater lake provides access to the submerged cave. A 10-12 m wide passage extends to the northeast from the lake for several hundred meters at $50 \mathrm{~m}$ depth, before opening into a $50 \mathrm{~m}$ wide collapsefloored room. This circular room contains a large breakdown mound in the center with an air dome above, but no apparent opening to the outside. Several large root masses, penetrating through cracks in the ceiling, hang down into the pool. A Hydrolab DataSonde 3 water quality analyzer carried by a diver was used to profile the water column in the terminal breakdown chamber (Fig. 13). Salinity increased from $9.8 \mathrm{ppt}$ at the surface, to $32.7 \mathrm{ppt}$ at $14 \mathrm{~m}$ depth and then more gradually to $34.8 \mathrm{ppt}$ at $46 \mathrm{~m}$ depth. Temperature increased from $26.7 \mathrm{de}$ grees $C$ at the surface, to a maximum of 29.1 degrees $\mathrm{C}$ between 14 and $19 \mathrm{~m}$ and then dropped in several steps to 23.8 degrees $\mathrm{C}$ at $46 \mathrm{~m}$ depth.
Dissolved oxygen (DO) concentration dropped rapidly from $1.06 \mathrm{mg} / \mathrm{l}$ at the surface to $0.1 \mathrm{mg} / \mathrm{l}$ at 2 $\mathrm{m}$ depth and stayed below $0.5 \mathrm{mg} / \mathrm{l}$ to $20 \mathrm{~m}$ where it increased steadily to $3.5 \mathrm{mg} / \mathrm{l}$ at $46 \mathrm{~m}$. The $\mathrm{pH}$ at the surface was 7.0 ; it spiked from 6.9 at $2.6 \mathrm{~m}$ to 7.4 at $3.2 \mathrm{~m}$ and was followed by a general increase to 7.55 at $46 \mathrm{~m}$ depth. The low DO layer corresponded to a murky, hydrogen sulfide zone. Most animals, including remipedes, were observed and collected from the clear, marine saline water below the hydrogen sulfide zone at 25 to $40 \mathrm{~m}$ depth. Remipedes were observed swimming in the water column and were collected either by hand in individual vials or with a suction bottle.

Other animals present in the terminal breakdown chamber where the remipedes were collected included copepods (three genera of undescribed epacteriscids and many other unknown species; A. Fosshagen, pers. commun.); the halocyprid ostracodes Danielopolina exuma and Deeveya medix; the leptostracan Speonebalia sp.; the peracarid Thetispelecaris remix; the amphipods Bahadzia sp. and Socarnopsis catacumba; a thermosbaenacean, probably Tulumella sp.; a mysid, probably Stygiomysis sp.; and the polynoid polychaete Pelagomacellicephala iliffei. All of these organisms are caveadapted, stygobiontic taxa characteristic of hydrologically isolated anchihaline caves. Copepod taxonomist Audun Fosshagen of the University of Bergen considered Basil Minns Blue Hole one of the most interesting copepod caves in the Bahamas.

\section{Some remarks on the biogeography and evolutionary history of Remipedia}

The three species described herein present another remarkable example of sympatry for remipedes, especially since these crustaceans are exclusively known from marine subterranean habitats. Groundwater environments are typically characterized by a limitation of nutrients and, in part as a consequence, low abundances of stygobiont organisms. The fact that remipedes are hermaphrodites may also point towards an adaptation to small population sizes. Interestingly, the sympatry of the three new species described herein is not exceptional for 

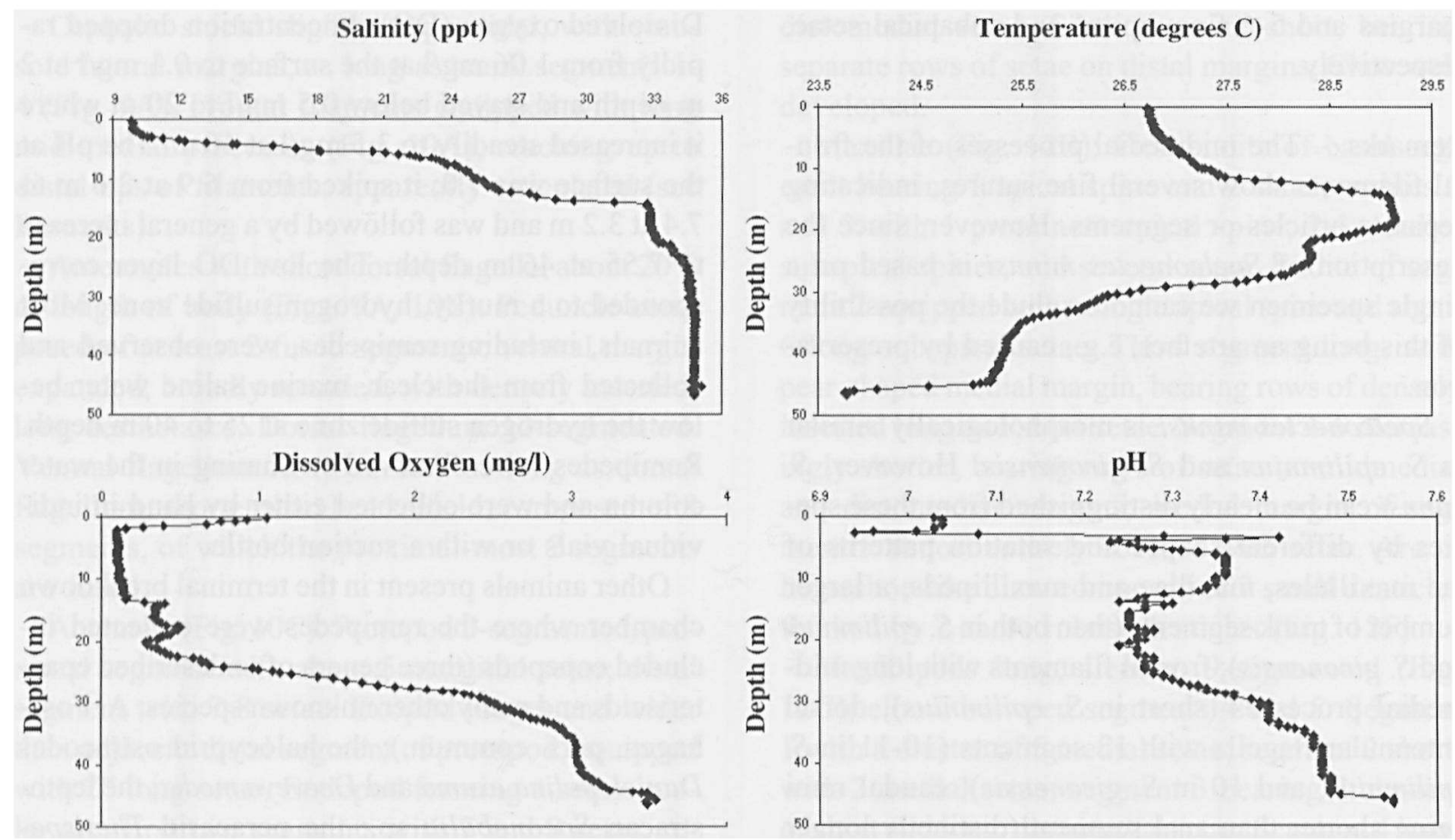

Fig. 13. Water column profile of salinity, temperature, dissolved oxygen and $\mathrm{pH}$ versus depth in the terminal breakdown room of Basil Minns Blue Hole, Great Exuma Island, Bahamas. Data were collected with a Hydrolab DataSonde 3 water quality analyzer carried by a diver.

Remipedia. There are several other instances of two or three sympatric species (Tab. 1). However, sympatric remipedes are known only from the Bahamas and nearby West Indian islands (Fig. 14). The high abundance of remipedes and their taxonomic diversity at and below the family level in this region forms a sharp contrast to the disjunct occurrences of a few remote taxa. The Remipedia in the northwestern region of the West Indies and the Bahamas comprise 12 species (6 genera and 2 families). Of the remaining three taxa, $S$. tulumensis Yager, 1987b, from the Yucatan Peninsula could be regarded as a peripheral isolate of the main cluster. By contrast, $S$. ondinae (Garcia-Valdecasas, 1984) from the Canary Islands and L. exleyi Yager \& Humphreys, 1996, from western Australia are extreme disjunct occurrences (Fig. 15).

The high availability of suitable habitats (anchihaline caves) within a relatively small region (Bahamas, West Indies) may have had, and still have, an important impact on the unique geographic distribution of Remipedia. In this light, the frequent occurrences of sympatry could be result of dispersal and, subsequently, multiple invasions of available anchihaline caves.

Sympatric remipedes are likely to be subjected to strong competition, which could lead either to niche differentiation or competitive exclusion. For example, the new species $S$. tanumekes (12 specimens collected) seems to be more abundant than $S$. parabenjamini ( 2 specimens) and $S$. minnsi ( 1 specimen). However, whether this is a sampling bias, a seasonal fluctuation or indeed related to population dynamics of the three remipedes in Basil Minns Blue Hole needs to be confirmed by additional collections.

Since their discovery, a plethora of opinions has been offered regarding the evolutionary history and phylogenetic status of Remipedia (see any Invertebrate Zoology textbook). Yet, we can be fairly certain that Remipedia are an ancient group of crustaceans. Remipedes share several well defined features with the Carboniferous fossil Tesnusocaris goldichi Brooks, 1955, from the Tesnus Forma- 


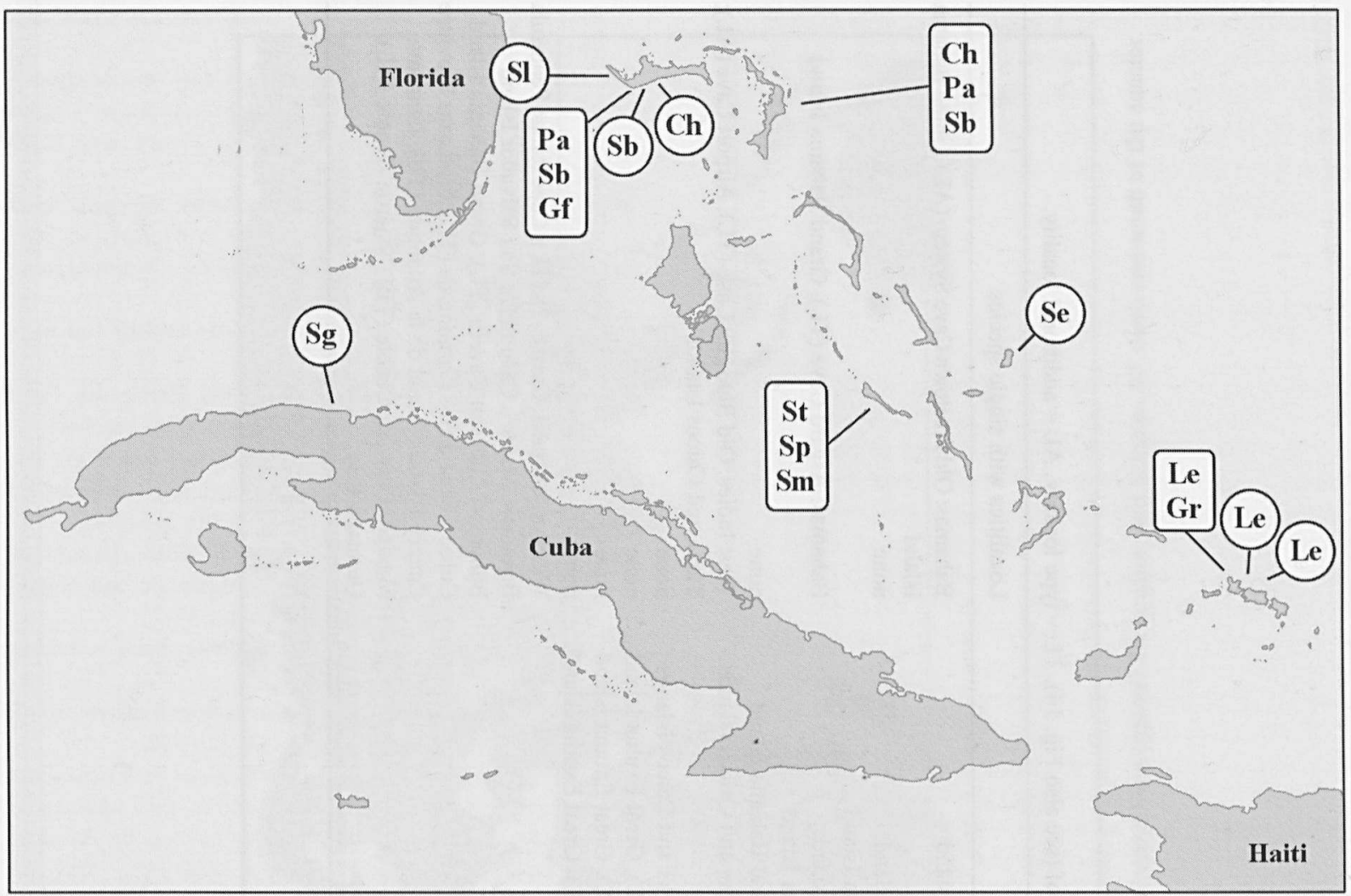

Fig. 14. Geographic distribution of Remipedia on the Bahamas and in the northwestern West Indies, including 12 of a total of 15 species known to science. Rectangular labels indicate occurrences of two or three sympatric species; circles show records of nonsympatric occurrences. Abbreviated taxa: $\mathrm{Ch}=$ Cryptocorynetes haptodiscus; $\mathrm{Gf}=$ Godzilliognomus frondosus; $\mathrm{Gr}=\mathrm{Godzillius}$ robustus; $\mathrm{Le}=$ Lasionectes entrichoma $; \mathrm{Pa}=$ Pleomothra apletocheles; $\mathrm{Sb}=$ Speleonectes benjamini $; \mathrm{Se}=S$. epilimnius $; \mathrm{Sg}=S$. gironensis; $\mathrm{Sl}=S$. lucayensis; $\mathrm{Sp}=S$. parabenjamini $\mathrm{n}$. $\mathrm{sp}$.; $\mathrm{Sm}=S$. minnsi $\mathrm{n}$. $\mathrm{sp}$.; $\mathrm{St}=S$. tanumekes $\mathrm{n}$. $\mathrm{sp}$.

tion (Upper Mississippian/Lower Pennsylvanian) in Texas (see Emerson \& Schram, 1991, for a detailed redescription). The most distinctive shared characters comprise a homonomously segmented trunk equipped with paddle-shaped, biramous swimming appendages, and the modification of three postoral cephalic appendages as subequal prehensile limbs. However, does the global, circum-tropical distribution of remipedes support an ancient origin for this group? Such disjunct occurrences of taxa are often interpreted as relicts of an ancient marine distribution, as postulated for various crustacean stygobionts, e.g., hadziid and bogidiellid amphipods (Stock, 1981; Holsinger, 1986; Koenemann \& Holsinger, 1999). Alternative theories favor a deep-sea origin for some stygobiontic crustaceans (Wilson, 1999; Manning et al., 1986; Hart et al.,
1985). These theories are particularly interesting since all remipedes occur in regions that are comparatively young in geological time. For example, the Canary Islands were probably formed during the Late Tertiary, and anchihaline cave systems resulting from volcanic activity, such as lava tubes, must have been colonized subsequently. Yet, we have to be careful not to jump to conclusions. Too little is still known about the biology of Remipedia, and at present, each additional discovery seems to add a piece to a more complete mosaic. The current distribution consists of a prominent cluster of taxa in the northern Caribbean region including the Bahamas. Whether this cluster is an ancient center of origin and the disjunct taxa are isolated relicts remains to be seen. At this point, it is equally conceivable that we are observing a distribution pat- 


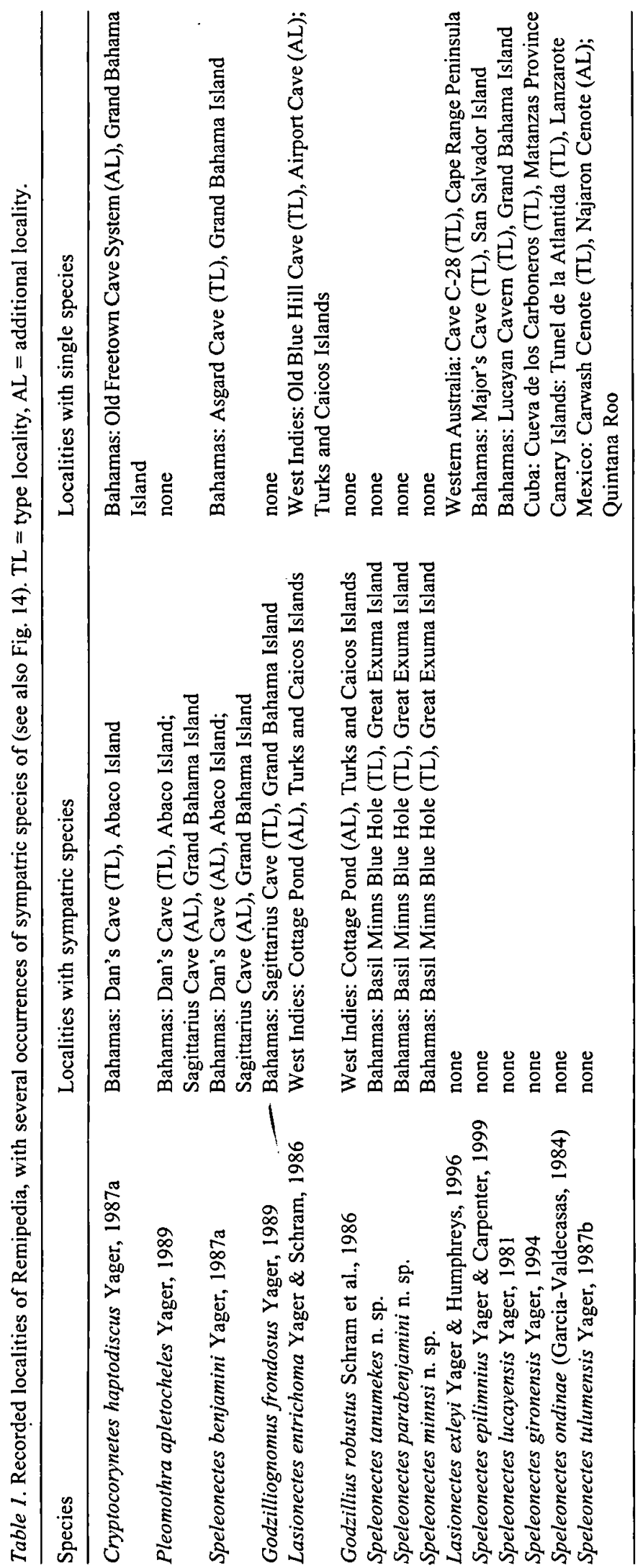




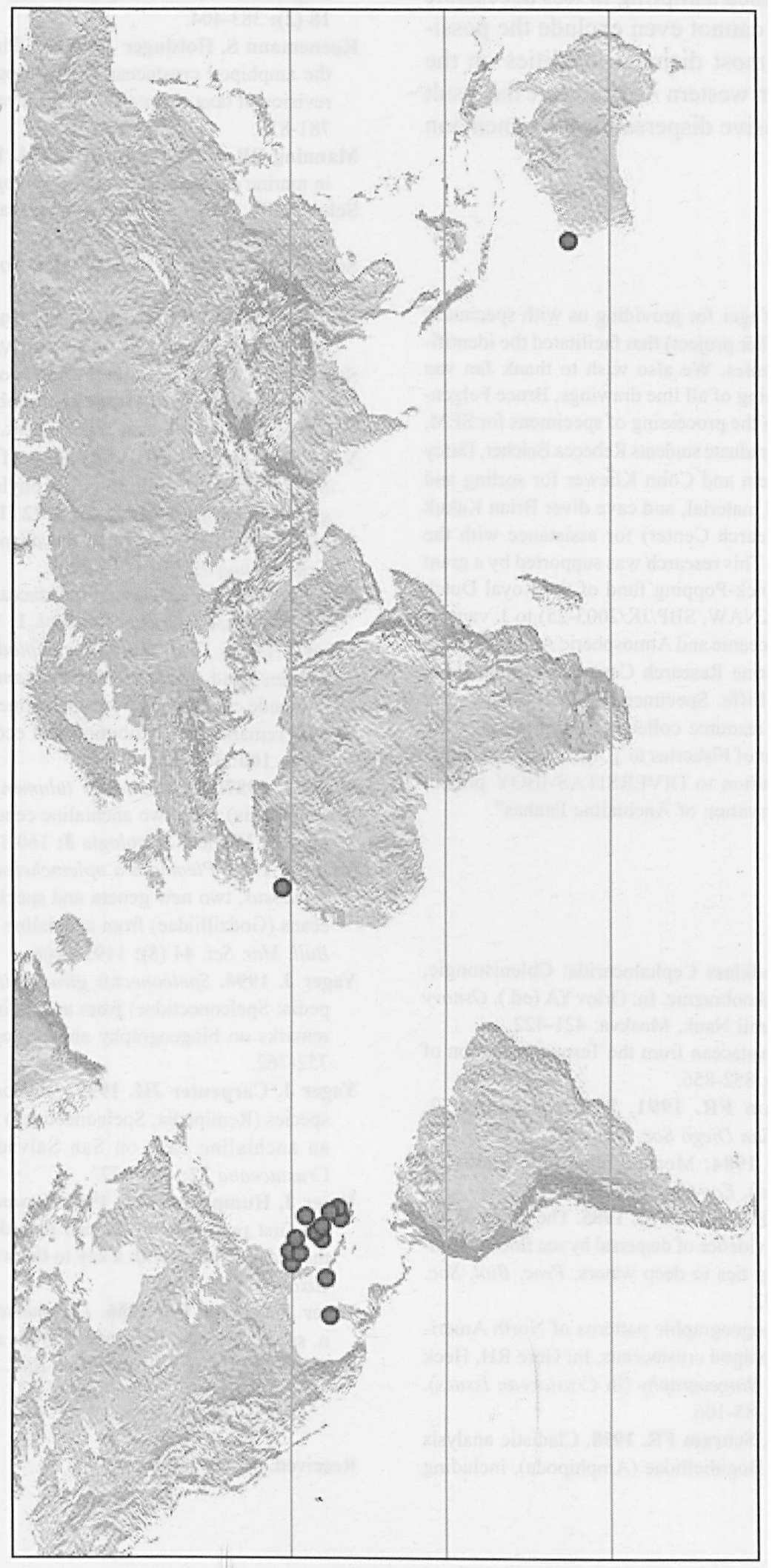

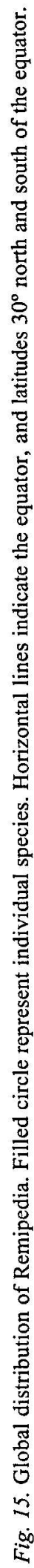


tern subjected to biased sampling in less accessible diving regions. We cannot even exclude the possibility that the two most disjunct localities on the Canary Islands and in western Australia are the result of some kind of passive dispersal (see Koenemann et al. 1998).

\section{Acknowledgments}

We are grateful to Jill Yager for providing us with specimens (in connection with another project) that facilitated the identification of these new species. We also wish to thank Jan van Arkel for digital processing of all line drawings, Bruce Felgenhauer for assistance with the processing of specimens for SEM, Texas A\&M University graduate students Rebecca Belcher, Darcy Gibbons, Lara Hinderstein and Colin Kliewer for sorting and photographing collected material, and cave diver Brian Kakuk (Caribbean Marine Research Center) for assistance with the collection of specimens. This research was supported by a grant from the Schure-Beijerinck-Popping fund of the Royal Dutch Academy of Sciences (KNAW, SBP/JK/2003-25) to J. van der $\mathrm{Ham}$, and the National Oceanic and Atmospheric Administration (NOAA) Caribbean Marine Research Center at Lee Stocking Island, Bahamas, to T. Iliffe. Specimens described here were collected under marine resource collecting permits issued by the Bahamas Department of Fisheries to T. Iliffe and B. Kakuk. This paper is a contribution to DIVERSITAS-IBOY project "Exploration and Conservation of Anchialine Faunas".

\section{References}

Birshtein YA. 1960. Podklass Cephalocarida: Chlenistongie, Trilobitoobraznie, Rakoobraznie. In: Orlov YA (ed.). Osnovy Paleontologii. Akademii Nauk, Moskva: 421-422.

Brooks IIK. 1955. A crustacean from the Tesnus formation of Texas. J. Paleont. 29: 852-856.

Emerson MJ, Schram FR. 1991. Remipedia, Par 2, Paleontology. Proc. San Diego Soc. Nat. Hist. 7: 1-52.

Garcia-Valdecasas A. 1984. Morlockiidae new family of Remipedia (Crustacea). Eos 60: 329-333.

Hart CW jr, Manning RB, Iliffe, TM. 1985. The fauna of Atlantic marine caves: Evidence of dispersal by sea floor spreading while maintaining ties to deep waters. Proc. Biol. Soc. Wash. 98 (1): 288-292.

Holsinger JR. 1986. Zoogeographic patterns of North American subterranean amphipod crustaceans. In: Gore RH, Heck $\mathrm{KL}$, eds. Crustacean Biogeography (in Crustacean Issues). Rotterdam: Balkema, 85-106.

Koenemann S, Vonk R, Schram FR. 1998. Cladistic analysis of 37 Mediterranean Bogidiellidae (Amphipoda), including
Bogidiella arista, new species, from Turkey. J. Crust. Biol. 18 (2): 383-404.

Koenemann S, Holsinger JR. 1999. Phylogenetic analysis of the amphipod crustacean family Bogidiellidae, s. lat., and revision of taxa above the species level. Crustaceana 72 (8): 781-816.

Manning RB, Hart JW jr, Iliffe TM. 1986. Mesozoic relicts in marine caves of Bermuda. Stygologia 2 (1/2): 156-166.

Schram FR. 1974. Late Paleozoic Peracarida of North America. Fieldiana: Geology 33: 95-124.

Schram FR. 1986. Crustacea. New York: Oxford University Press.

Schram FR, Yager J, Emerson MJ. 1986. Remipedia. Part I. Systematics. Mem. San Diego Soc. Nat. Hist. 15: 1-60.

Stock J.H. 1981. The taxonomy and zoogeography of the family of Bogidiellidae (Crustacea, Amphipoda), with emphasis on the West Indian taxa. Bijdr. Dierk. 51: 345-374.

Vonk R, Schram FR. 2003. Ingolfiellidea (Crustacea, Malacostraca, Amphipoda): a phylogenetic and biogeographic analysis. Contrib. Zool. 72 (1): 39-72.

Wilson GDF. 1999. Some of the deep-sea fauna is ancient. Crustaceana 72 (8): 1019-1030.

Yager J. 1981. A new class of Crustacea from a marine cave in the Bahamas. J. Crustacean Biol. 1: 328-333.

Yager J. 1987a. Cryptocorynetes haptodiscus, new genus, new species, and Speleonectes benjamini, new species, of remipede crustaceans from anchialine caves in the Bahamas, with remarks on distribution and ecology. Proc. Biol. Soc. Wash. 100: 302-320.

Yager J. 1987b. Speleonectes tulumensis, n. sp. (Crustacea, Remipedia) from two anchialine cenotes of the Yucatan Peninsula, Mexico. Stygologia 3: 160-166.

Yager J. 1989. Pleomothra apletocheles and Godzilliognomus frondosus, two new genera and species of remipede crustaceans (Godzilliidae) from anchialine caves of the Bahamas. Bull. Mar. Sci. 44 (3): 1195-1206.

Yager J. 1994. Speleonectes_gironensis, new species (Remipedia: Speleonectidae) from anchialine caves in Cuba, with remarks on biogeography and ecology. J. Crust. Biol. 14: 752-762.

Yager J, Carpenter JH. 1999. Speleonectes epilimnius new species (Remipedia, Speleonectidae) from surface waters of an anchialine cave on San Salvador Island, Bahamas. Crustaceana 72: 965-977.

Yager J, Humphreys WF. 1996. Lasionectes exleyi, sp. nov., the first remipede crustacean recorded from Australia and the Indian Ocean, with a key to the world species. Invertebr. Taxon. 10: 171-187.

Yager J, Schram FR. 1986. Lasionectes entrichoma, n. gen., n. sp. (Crustacea, Remipedia) from anchialine caves in the Turks and Caicos, B.W.I. Proc. Biol. Soc. Wash. 99 (1): 6570.

Received: 8 May 2003 